VATT Working Papers 131

\title{
Optimal Patent Policy for Pharmaceutical Industry
}

Olena Izhak

Tanja Saxell

Tuomas Takalo 


\title{
VATT WORKING PAPERS
}

\section{1 \\ Optimal Patent Policy for Pharmaceutical Industry}

\author{
Olena Izhak \\ Tanja Saxell \\ Tuomas Takalo
}


Olena Izhak, Düsseldorf Institute for Competition Economics, olena.izhak@gmail.com

Tanja Saxell, VATT Instute for Economic Research, tanja.saxell@vatt.fi

Tuomas Takalo, Bank of Finland and VATT, tuomas.takalo@bof.fi

We thank Vanessa Behrens, Vincenzo Denicolò, Alberto Galasso, Matthew Grennan, Dietmar Harhoff, Jussi Heikkilä, Ari Hyytinen, William Kerr, Matthew Mitchell, Petra Moser, Benjamin Roin, Mark Schankerman, Carlos Serrano, Morten Sæthre, Ashley Swanson, Robert Town, Janne Tukiainen, Hannes Ullrich, Rosemarie Ziedonis, and audiences of numerous seminars and conferences for useful comments and discussions. We gratefully appreciate the hospitality of the Economics Departments at Boston and Stanford Universities, and Health Care Management Department of Wharton School where parts of this research has been conducted. We also gratefully acknowledge funding from Yrjö Jahnsson Foundation.

ISBN 978-952-274-253-7 (PDF)

ISSN 1798-0291 (PDF)

URN:ISBN:978-952-274-253-7

Valtion taloudellinen tutkimuskeskus

VATT Institute for Economic Research

Arkadiankatu 7, 00100 Helsinki, Finland

Helsinki, May 2020 


\title{
Optimal Patent Policy for Pharmaceutical Industry*
}

\author{
Olena Izhak \\ Düsseldorf Institute for \\ Competition Economics
}

Tanja Saxell

VATT

May 10, 2020

\begin{abstract}
We show how characterizing optimal patent policy for the pharmaceutical industry only requires information about generic producers' responses to changes in the effective duration and scope of new drug patents. To estimate these responses, we use data on Paragraph IV patent challenges, and two quasi-experimental approaches: one based on changes in patent laws and another on the allocation of patent applications to examiners. We find that extending effective patent duration increases generic entry via Paragraph IV patent challenges whereas broadening protection reduces it. Our results imply that pharmaceutical patents should be made shorter but broader.
\end{abstract}

Keywords: Patent policy, pharmaceuticals, generic entry, innovation, imitation

*We thank Vanessa Behrens, Vincenzo Denicolò, Alberto Galasso, Matthew Grennan, Dietmar Harhoff, Jussi Heikkilä, Ari Hyytinen, William Kerr, Matthew Mitchell, Petra Moser, Benjamin Roin, Mark Schankerman, Carlos Serrano, Morten Sæthre, Ashley Swanson, Robert Town, Janne Tukiainen, Hannes Ullrich, Rosemarie Ziedonis, and audiences of numerous seminars and conferences for useful comments and discussions. We gratefully appreciate the hospitality of the Economics Departments at Boston and Stanford Universities, and Health Care Management Department of Wharton School where parts of this research has been conducted. We also gratefully acknowledge funding from Yrjö Jahnsson Foundation. Contacts: olena.izhak@gmail.com, tanja.saxell@vatt.fi, tuomas.takalo@bof.fi. 


\section{Introduction}

Patent policy aims at stimulating innovation by providing exclusive rights to innovators at the cost of reduced competition. This tradeoff between competition and innovation incentives is at the core of the mature theoretical literature on the optimal design of patent length and scope, dating back to the seminal works by Nordhaus (1969) and (1972). Empirical studies such as Sakakibara and Branstetter (2001), Moser (2005), Quian (2007), and Lerner (2009)) provide estimates of the effects of patent policy reforms on innovation. ${ }^{1}$ However, these empirical results are not enough to guide the optimal design of patent length and scope. We combine theory and two-quasi experimental approaches to characterize optimal patent policy for the US pharmaceutical industry. Our results indicate that the terms of pharmaceutical patents should probably be shorter and their scope broader. The key mechanism behind our conclusion is the positive effect of longer patent duration on early generic entry: we find that one year increase in effective patent length increases generic entry before the expiration of new drug patents by roughly five percentage points. These results support the theory of costly imitation pioneered by Gallini (1992), which points to the optimality of broad but short-lived patents because long-lasting patents encourage to invent around those patents.

The US pharmaceutical industry provides a well-defined setting to assess the theory of costly imitation: The Drug Price Competition and Patent Term Restoration Act of 1984 (aka the "HatchWaxman" Act) introduced generic drug applications with Paragraph IV (PIV) certifications. In such a drug application a generic firm certifies noninfringement or invalidity of a new drug patent, allowing the FDA to approve the application before the expiration of that patent. Hemphill and Sampat (2011a) and Branstetter et al. (2016) document a substantial increase in such PIV patent challenges during this millennium.

Our theoretical model shows how characterizing optimal pharmaceutical patent policy only requires information about generic firms' entry responses to changes in the effective length and scope of new drug patents. We estimate the impact of effective patent length on the probability of PIV entry (that is, a successful PIV patent challenge by a generic entrant). We exploit two patent law reforms inducing quasi-experimental variation in the effective terms of patents depending on their prosecution time at the U.S. Patent and Trademark Office (USPTO): First, the Agreement on

\footnotetext{
${ }^{1}$ Denicolò (1996) and Belleflamme and Peitz (2015, Chapter 19) synthesize the theoretical literature and Boldrin and Levine (2013), Moser (2013), and Budish et al. (2016) survey the empirical evidence.
} 
Trade-Related Aspects of Intellectual Property (TRIPS) of 1994 changed the statutory patent term from 17 years from the grant date to 20 years from the first filing date. TRIPS also introduced patent term adjustments (PTAs) to compensate for some delays in patent prosecution, but we document that those USPTO PTAs were initially insignificant. Second, the American Inventors Protection Act (AIPA) of 1999 expanded PTAs to compensate for long delays in patent prosecution. We show how the two reforms affected the effective terms of patents with grant lags exceeding three years, whereas the effective terms of patents with shorter grant lags were hardly changed.

Using difference-in-differences (DiD) regressions, we find that TRIPS decreased the effective terms of patents prosecuted at least three years by 17 percent, compared to other patents. This shorter effective patent length reduced the rate of PIV entry around 8-10 percentage points. In contrast, AIPA increased the effective terms of patents with the long prosecution lags by 10 percent, which in turn increased the rate of PIV entry by seven percentage points. These results, together with supporting evidence from ordinary least squares (OLS) regressions, indicate that longer patent duration increases PIV entry.

Using multiple measures of patent scope and OLS regressions, we also provide evidence that broadening patent scope reduces PIV entry. To address the endogeneity of patent scope, we develop instrumental variables (IV) for some of our scope measures by exploiting differences in the propensity of some patent examiners to grant broader or more claims. The evidence from our IV regressions - though not conclusive given the lack of fully randomized examiner assignment (see Righi and Simcoe, 2019) - implies that extending the scope of patent claims decreases the probability of PIV entry by about two percentage points.

Our theoretical model yields two formulas characterizing optimal patent policy. These formulas require as key inputs an estimate of the elasticity of PIV entry with respect to effective patent length or patent scope. Based on the DiD and IV estimates, we extrapolate the elasticity of PIV entry with respect to effective length and scope to be around three and -1 , respectively. Using these elasticity estimates in our formulas allows us to predict the effects of changes in patent length and scope on innovation and welfare. The results point to the optimality of shorter patent length, which should be compensated by broadening the scope of protection. This conclusion is at odds with some policies of balancing competition and innovation incentives in the pharmaceutical industry. For example, the Drug Price Competition and Patent Term Restoration Act - as its name suggests 
- simultaneously lengthened pharmaceutical patent terms and narrowed their scope by introducing the FDA patent term extension and PIV patent challenge mechanisms.

Our model builds on the theory of costly imitation developed by Gallini (2002) and later expanded by, e.g., Takalo (1998), Wright (1999), and Maurer and Scotchmer (2002). Our empirical results concerning patent length are consistent with the findings in Lerner (2009) and Giorcelli and Moser (2019) showing little effects of longer duration of intellectual property rights on innovation and creative work. To identify the effects of patent length, we build on the studies on the effects of TRIPS (e.g., Abrams, 2009; Kyle and McGahan, 2012) and of commercialization lags (Budish et al., 2015) on innovation in the pharmaceutical industry. To identify the effects of patent scope, we draw on Kuhn and Thompson (2019), Sampat and Williams (2019) and Farre-Mensa et al. (2020) who develop similar examiner-leniency IVs. Methodologically, our approach is also close to Denicolò (2007) and Budish et al. (2016) who emphasize the estimation of innovation elasticities for the design of optimal patent policy. We complement these papers by estimating the effects of changes in patent length and scope on generic entry. Moreover, by using these estimates in our theoretical formulas, we can characterize optimal patent policy without using data on innovating firms.

A limitation of our study is that we abstract away from the issues related to the effects of patents on cumulative innovation (e.g., Galasso and Schankerman, 2015; Sampat and Williams, 2019).

\section{Optimal Pharmaceutical Patent Length and Scope: Theory}

\subsection{The Model}

We consider a pharmaceutical drug market where two firms, an originator (brand) drug manufacturer (firm B) and a generic drug manufacturer (firm G), interact. The originator firm can invest in developing a new drug, automatically protected by a patent. The generic firm can invest in challenging the new drug patent. ${ }^{2}$ We allow for no ex ante licensing. ${ }^{3}$

\footnotetext{
${ }^{2}$ The assumption of only one potential generic entrant is made for simplicity. However, the Drug Price Competition and Patent Term Restoration Act also stipulates the first successful PIV entrant at minimum a 180-day exclusivity period during which no further generic firms are allowed to enter. Allowing free entry to invent around patents would not qualitatively change the results (see, e.g., Gallini, 1992 and Wright, 1999).

${ }^{3}$ Optimal policy depends on the feasibility of ex ante licensing (see, e.g., Maurer and Scotchmer, 2002). We view our assumption as reflecting the pharmaceutical industry practice: Our data, as also the findings, e.g., in Hemphill and Sampat (2011a) and Branstetter et al. (2016), show that PIV challenges occur frequently, indicating a failure in the market for ex ante licenses. There is also little evidence of generic entry based on licensing prior to PIV challenges.
} 
Time $t \in[0, \infty)$ is continuous but, for brevity, we assume that the firms act sequentially at $t=0$ by directly choosing the success probabilities of their investments $p_{f} \in[0,1], f=B, G$. (Alternatively, we may think that the firms choose an investment project from a collection of projects indexed by $p_{f}$.) The success $Y_{f}:\{0,1\} \rightarrow\{0,1\}$ of the firm $f$ 's investment thus has a Bernoulli distribution with parameter $p_{f}$. The associated investment cost functions $C_{f}:[0,1] \rightarrow[0, \infty)$, $f=B, G$, are twice continuously differentiable with the standard properties $\partial C_{f} / \partial p_{f}>0$ and $\partial^{2} C_{f} / \partial p_{i}^{2}>0$ for $p_{f}>0$, and $C_{f}(0)=\partial C_{f}(0) / \partial p_{f}=0$. The cost functions are sufficiently convex to satisfy second-order conditions.

We consider two patent policy variables, length (term) $T \in[0, \infty)$ and scope (breadth) $b \in[0, \infty)$. (To simplify the proofs, we allow $b$ and $T$ to only take arbitrarily large but finite values.) As is common in the theoretical literature (see Budish et al., 2015, for an exception), we assume that a marketing authorization and a patent are granted to a new drug simultaneously upon the investment success realization $y_{B}=1$ at $t=0$, from which patent length is counted. Hence, $T$ reflects effective new drug patent length. Following Gallini (1992), we assume that the cost of challenging a valid new drug patent is increasing in $b$, i.e., $\partial C_{G}\left(p_{G}, b\right) / \partial b>0$. (Maurer and Scotchmer, 2002 argue for this way of modeling patent scope.) In our context, this assumption means that a broader new drug patent makes generic entry prior to the patent expiration more difficult. If a patent that has not been successfully challenged expires at some time $t=T, b=0$ for $t \geq T$ and generic entry will become costless, $C_{G}\left(p_{G}, 0\right)=0$. (This assumption can be relaxed in so far entry is cheaper after the patent expiration.)

After the realizations $y_{f} \in\{0,1\}$ of $Y_{f}, f=B, G$, the firms compete in the market. The net cash flow from selling a drug is given by $\widetilde{\pi}_{N} \in[0, \infty)$, in which subscript $N \in\{0,1,2\}$ denotes the number of competing drugs in the market. The drug market will exist only if $y_{B}=1$; otherwise $N=0$ and $\widetilde{\pi}_{0}=0$. Conditional on $y_{B}=1$, our assumptions imply that $N=1$ only if $t<T$ and $y_{G}=0$; otherwise $N=2$. For simplicity, we allow no perfect collusion and, hence, $\widetilde{\pi}_{1}>2 \widetilde{\pi}_{2}$. (The assumption of equal net cash flows in the case of a duopoly can be relaxed at the cost of complicating the notation.)

Reminiscent of the results in Wright (1999), the shape of the patent challenging cost function turns out to be crucial for the characterization of the optimal patent policy. We introduce the 
following definitions to characterize the shape of $C_{G}\left(p_{G}, b\right)$ :

$$
\epsilon_{p}:=p_{G} \frac{\partial^{2} C_{G} / \partial p_{G}^{2}}{\partial C_{G} / \partial p_{G}}
$$

and

$$
\epsilon_{b}:=p_{G} \frac{\partial^{2} C_{G} / \partial b \partial p_{G}}{\partial C_{G} / \partial b}
$$

In words, $\epsilon_{p}$ is the elasticity of the marginal cost of patent challenging, providing us with a measure of the convexity of the generic firm's cost function. To avoid the need to check out additional corners, we assume that $\epsilon_{p}>0$ for all $p_{G}$. (The additional restrictions here are mild, since our other assumptions imply that $\epsilon_{p}>0$ at least for $p_{G} \in(0,1)$.) In turn, $\epsilon_{b}$ is the elasticity of the impact of patent scope on patent challenging costs. Since $\partial C_{G} / \partial b>0$, the sign of $\epsilon_{b}$ is given by the sign of $\partial^{2} C_{G} / \partial p_{G} \partial b$. We proceed under the assumption that $\partial^{2} C_{G} / \partial b \partial p_{G}>0$, i.e.,

Assumption 1. $\epsilon_{b}>0$.

According to Assumption 1, the effect of patent scope on patent challenging costs is the stronger the easier is patent challenging. Besides shortening the analysis considerably, making this simplification has four justifications: First, as shown in Appendix A.1 where we we relax Assumption 1, effects of patent scope in the case $\epsilon_{b} \leq 0$ are counterintuitive. For example, if $\epsilon_{b}<0$, an increase in patent scope making patent challenging more expensive has a positive impact on the probability of a successful patent challenge. Such effects can be viewed as being in conflict with the definition of patent scope. Second, our results concerning patent length are do not depend on Assumption 1 (see Appendix A.1). Third, our empirical results of the negative effect of broader patent scope on PIV entry provide support for Assumption 1. Fourth, this assumption is often implicitly done in the previous literature modelling imitation costs as a function of patent scope.

We consider the following two-stage game: In the first stage the originator firm first chooses its success probability $p_{B}(b, T) \in[0,1]$. In the second stage, after observing $Y_{B}=y_{b}$, the generic firm chooses $p_{G}\left(y_{B}, b, T\right) \in[0,1]$. The outcome $y_{G} \in\{0,1\}$ of that investment is realized. The firms collect their payoffs depending on the realizations of $Y_{f}, f=B, G$, and patent length $T$. Denote the firm $f$ 's expected profit by $\Pi_{f}, f=B, G$. A subgame perfect equilibrium of this game is a pair $\left(p_{B}^{*}, p_{G}^{*}\left(y_{B}\left(p_{B}\right)\right)\right)$ such that for all $y_{B}\left(p_{B}\right) \in\{0,1\}, p_{G}^{*}\left(y_{B}\left(p_{B}\right)\right)=\arg \max _{p_{G} \in[0,1]} \Pi_{G}\left(p_{G}, y_{B}\left(p_{B}\right)\right)$ 
and $p_{B}^{*}=\arg \max _{p_{B} \in[0,1]} \Pi_{B}\left(p_{B}, p_{G}^{*}\left(y_{B}\left(p_{B}\right)\right)\right)$.

\subsection{Equilibrium Incentives for New Drug Development and Patent Challenging}

Consider the second stage of the game after the realization of $Y_{B}$. Clearly, if $y_{B}\left(p_{B}\right)=0$, the market for the new drug fails to arise, and $p_{G}^{*}=0$. In what follows, we therefore focus on determining the part of the equilibrium where the drug market exists, $\left(p_{B}^{*}, p_{G}^{*}\left(y_{B}\left(p_{B}\right)=1\right)\right)$, and suppress the argument $y_{B}\left(p_{B}\right)$ for brevity.

Given $y_{B}\left(p_{B}\right)=1$, the generic firm's problem can be written as

$$
\max _{p_{G} \in[0,1]} \Pi_{G}=p_{G} \int_{0}^{\infty} e^{-r t} \widetilde{\pi}_{2} d t+\left(1-p_{G}\right) \int_{T}^{\infty} e^{-r t} \widetilde{\pi}_{2} d t-C_{G}\left(p_{G}, b\right)
$$

in which $r \in[0, \infty)$ denotes the firms' common discount rate. The first integral on the righthand side of equation (3) captures the generic firm's profits if, with probability $p_{G}$, it successfully challenges the new drug patent. The second integral captures the profits if, with probability $1-p_{G}$, the challenge fails and the generic entry is postponed until the patent expiration. The last term captures the costs of patent challenging.

Using the definition $\pi_{2}:=\widetilde{\pi}_{2} / r$ yields the first-order condition for the problem (3) as

$$
\left(1-e^{-r T}\right) \pi_{2}-\frac{\partial C_{G}\left(p_{G}^{*}, b\right)}{\partial p_{G}}=0
$$

The solution to equation (4) implicitly determines the unique $p_{G}^{*}(b, T)$ conditional on $y_{B}\left(p_{B}\right)=1$.

In the first stage the originator firm chooses $p_{B}$. The private value of an approved new drug to the originator firm is given by

$$
V^{P}\left(T, p_{G}^{*}(b, T)\right)=\int_{0}^{T} e^{-r t}\left[\left(1-p_{G}^{*}(b, T)\right) \widetilde{\pi}_{1}+p_{G}^{*}(b, T) \widetilde{\pi}_{2}\right] d t+\int_{T}^{\infty} e^{-r t} \widetilde{\pi}_{2} d t
$$

in which $p_{G}^{*}(b, T)$ is determined by equation (4). The first term on the right-hand side of equation (5) depicts the originator firm's profits when its new drug patent is in force. The originator firm will be in a monopoly position if the generic firm's patent challenge fails (the first term in the square brackets) but will encounter generic competition if the patent challenge succeeds (the second 
term in the square-brackets). The second term expresses the originator firm's profits from generic competition after the patent expiration.

The originator firm's problem is given by

$$
\max _{p_{B} \in[0,1]} \Pi_{B}=p_{B} V^{P}\left(T, p_{G}^{*}(b, T)\right)-C_{B}\left(p_{B}\right),
$$

in which $V^{P}\left(T, p_{G}^{*}(b, T)\right)$ is given by equation (5) and the last term captures the costs of developing a new drug. The first-order condition for this problem is given by

$$
V^{P}\left(T, p_{G}^{*}(b, T)\right)-\frac{\partial C_{B}\left(p_{B}^{*}\right)}{\partial p_{B}}=0
$$

Equations (4) and (6) determine the unique subgame perfect equilibrium $\left(p_{B}^{*}, p_{G}^{*}\right)$ with an active drug market $\left(y_{B}\left(p_{B}\right)=1\right)$. We first characterize the behavior of $p_{G}^{*}$ :

Proposition 1: Increasing patent length or narrowing patent scope increases the probability of a successful patent challenge.

Proof: Applying the implicit function theorem to equation (4) yields

$$
\frac{\partial p_{G}^{*}}{\partial T}=\frac{r e^{-r T} \pi_{2}}{\partial^{2} C_{G} / \partial p_{G}^{2}}>0
$$

and

$$
\frac{\partial p_{G}^{*}}{\partial b}=-\frac{\partial^{2} C_{G} / \partial p_{G} \partial b}{\partial^{2} C_{G} / \partial p_{G}^{2}}<0
$$

in which the inequalities follow from the assumptions $\partial^{2} C_{G} / \partial p_{G}^{2}>0$ and $\partial^{2} C_{G} / \partial p_{G} \partial b>0$.

Proposition 1 confirms the standard results arising from the models of patent policy with costly imitation like ours: A longer patent duration makes waiting for patent expiration less attractive and hence stimulates investments to challenge new drug patents, whereas broader patents discourage patent challenging by increasing its costs.

To facilitate the characterization of the impacts of patent length and scope on incentives to develop new drugs and the optimal patent policy in the next subsection, we define

$$
f\left(p_{G}\right):=\epsilon_{p}-\frac{p_{G}}{1-p_{G}}
$$


in which $\epsilon_{p}>0$ is defined by equation (1). Then, we have the following result:

Proposition 2: Broader patent scope increases incentives to develop new drugs. Increasing (decreasing) patent length increases incentives to develop new drugs if $f\left(p_{G}^{*}\right)>0\left(f\left(p_{G}^{*}\right)<0\right)$.

Proof: Using the implicit function theorem in equation (6) together with $\partial^{2} C_{B} / \partial p_{B}^{2}>0$ imply that the signs of $\partial p_{B}^{*} / \partial b$ and $\partial p_{B}^{*} / \partial T$ are given by the signs of $\partial V^{P} / \partial b$ and $\partial V^{P} / \partial T$, respectively. Then, differentiating equation (5) with respect to $b$ and using the definition $\pi_{N}:=\widetilde{\pi}_{N} / r$ yield

$$
\frac{\partial V^{P}}{\partial b}=-\left(1-e^{-r T}\right)\left(\pi_{1}-\pi_{2}\right) \frac{\partial p_{G}^{*}}{\partial b}
$$

in which $\partial p_{G}^{*} / \partial b<0$ by Proposition 1 . The claim concerning patent scope follows.

Similarly, differentiating equation (5) with respect to $T$ gives

$$
\frac{\partial V^{P}}{\partial T}=\left(\pi_{1}-\pi_{2}\right)\left[r e^{-r T}\left(1-p_{G}^{*}\right)-\frac{\partial p_{G}^{*}}{\partial T}\left(1-e^{-r T}\right)\right]
$$

After using equations (1), (4), and (7), we can rewrite this equation as

$$
\frac{\partial V^{P}}{\partial T}=\frac{r e^{-r T}}{\epsilon_{p}}\left(\pi_{1}-\pi_{2}\right) f\left(p_{G}^{*}\right)\left(1-p_{G}^{*}\right)
$$

in which $f\left(p_{G}\right)$ is defined by equation (9). As a result the sign of $\partial V^{P} / \partial T$ and, by implication, the sign of $\partial p_{B}^{*} / \partial T$ is given by the sign of $f\left(p_{G}^{*}\right)$. The claim concerning patent length follows.

Propositions 1 and 2 suggest, as is intuitive, that the sign of $\partial p_{B}^{*} / \partial b$ is the reverse of the sign of $\partial p_{G}^{*} / \partial b$ : broader patent scope weakens incentives to challenge new drug patents which in turn enhances incentives to develop new drugs.

In contrast, patent length has both a direct and an indirect effect on incentives to develop new drugs. The direct effect, captured by the first term in the square-brackets of equation (11), is positive: if there is no generic entry, the originator firm's monopoly lasts longer. However, the indirect effect via $p_{G}^{*}$ (the second-term in the square-brackets of equation (11)) is negative: as suggested by Proposition 1, a longer patent duration enhances incentives to challenge new drug patents. Hence, an increase in patent length can have a positive or a negative effect on incentives to develop new drugs depending on whether the direct or indirect effect dominates which in turn 
depends on the sign of $f\left(p_{G}^{*}\right)$ of equation $(9)$.

With mild additional assumptions $\left(\partial f / \partial p_{G}<0\right.$ and $\left.\lim _{T \rightarrow \infty} f\left(p_{G}^{*}(T)\right)<0\right)$, these direct and indirect effects of patent length would create the inverted-U relationship between patent length and innovation incentives (with the peak at some $T^{\prime}$ solving $f\left(p_{G}^{*}\left(T^{\prime}\right)\right)=0$ ), which has been discovered in the literature (see, e.g., Gallini, 2002; Quian, 2007). When a patent is sufficiently short lived, the probability of a successful patent challenge is sufficiently low to guarantee that the direct effect of patent length on incentives for new drug development dominates. As a result, increasing patent length enhances new drug development. However, when patent protection lasts sufficiently long, the probability of a successful patent challenge becomes so high that the indirect effect dominates and renders the impact of patent length on new drug development negative.

\subsection{Optimal Patent Policy}

Let us denote welfare flow from a new drug by $\widetilde{w}_{N} \in[0, \infty)$ when $N \in\{0,1,2\}$ drugs are competing in the market. As usual, $w_{N+1}>w_{N}$ and $w_{0}=0$. Let $w_{N}:=\widetilde{w}_{N} / r$ denote the discounted welfare from the new drug.

Analogous to the private value of a new drug given by equation (5), we can write the social value of an existing new drug as

$$
\begin{aligned}
V^{S}(b, T)= & \int_{0}^{T} e^{-r t}\left[\left(1-p_{G}^{*}(b, T)\right) \widetilde{w}_{1}+p_{G}^{*}(b, T) \widetilde{w}_{2}\right] d t \\
& +\int_{T}^{\infty} e^{-r t} \widetilde{w}_{2} d t-C_{G}\left(p_{G}^{*}(b, T), b\right),
\end{aligned}
$$

in which $p_{G}^{*}(b, T)$ is given by equation (4). The first and second term on the right-hand side of equation (13) give welfare from a new drug before and after its patent expires, respectively. The last term captures the generic firm's investment cost.

The total (ex ante) welfare from a new drug is then given by

$$
W(b, T)=p_{B}^{*}(b, T) V^{S}(b, T)-C_{B}\left(p_{B}^{*}(b, T)\right)
$$

in which $p_{B}^{*}(b, T)$ and $V^{S}(b, T)$ are given by equations (6) and (13), respectively, and $C_{B}\left(p_{B}(b, T)\right)$ is the originator firm's cost of developing a new drug. 
Following the standard practice, we determine the socially optimal combination of patent length and scope in the pharmaceutical industry by maximizing the social surplus from a new drug, keeping incentives for new drug development fixed at a desired level $\bar{p}_{B}$. The regulator's problem can thus be expressed as

$$
\max _{b \in[0, \infty), T \in[0, \infty)} V^{S}(b, T)
$$

subject to

$$
p_{B}^{*}(b, T)=\bar{p}_{B}
$$

Recalling that $\epsilon_{b}>0$ (Assumption 1) the optimal patent policy can be characterized as follows:

Proposition 3: i) If $f\left(p_{G}^{*}\right)<0$, it is optimal to reduce both patent length and patent scope; ii) If $\epsilon_{b}>f\left(p_{G}^{*}\right)>0$, it is optimal to reduce patent length and increase patent scope; iii) If $f\left(p_{G}^{*}\right)>\epsilon_{b}$, it is optimal to reduce patent scope and increase patent length.

Proof: In Appendix A.1.

We may explain Proposition 3 as follows: If $\epsilon_{b}>f\left(p_{G}^{*}\right)$, short-lived patents are optimal irrespective of the sign of $f\left(p_{G}^{*}\right)$. This result tends to arise from the models of costly imitation. In our context, a possibility to challenge new drug patents makes longer patent duration an inefficient way to promote new drug development, since it also increases incentives for patent challenging.

When short-lived patents are optimal, the sign of $f\left(p_{G}^{*}\right)>0$ determines the optimal direction of adjusting patent scope. If $f\left(p_{G}^{*}\right)>0$, shorter patent length has an adverse effect on incentives to develop new drugs and it should be compensated by making patents broader. If $f\left(p_{G}^{*}\right)<0$, patent challenging is so lucrative that shortening patent length has a positive effect on incentives to develop new drugs, and patents can be made narrower without jeopardizing new drug development. Thus the sign of $f\left(p_{G}^{*}\right)$ also determines whether patent length and scope are substitutable or complementary policy tools with regard to new drug development.

Nonetheless, even in the presence of costly imitation, it is possible that narrow and long-lived patents are optimal. Here this scenario happens when $f\left(p_{G}^{*}\right)>\epsilon_{b}$. A small $\epsilon_{b}$ makes increasing patent scope less efficient since then it has only a relatively small impact on the generic firm's patent challenging incentives but a relatively large impact on its costs. Thus, distortions caused by broader patents can even be larger than distortions caused by longer patents. It is, however, difficult to 
come up with a cost function that would generate this outcome.

Example 1. Let us assume that the generic firm's cost function has a constant elasticity, and takes the form

$$
C_{G}\left(p_{G}, b\right)=\frac{c(b) p_{G}^{\eta_{G}}}{\eta_{G}}
$$

in which $\eta_{G}>1$ is a constant capturing the elasticity of the cost function, and $c(b) \geq 0$ denotes a constant scaling the cost function. Assume that this constant is an increasing function of patent scope, $\partial c / \partial b>0$.

The cost function specified by equation (16) implies that Assumption 1 holds and, as a result, Propositions 1 and 2 also hold with respect to patent scope.

As to the optimal policy, equation (16) implies that $\epsilon_{p}=\eta_{G}-1$ and we can rewrite equation (9) as

$$
f\left(p_{G}\right)=\eta_{G}-\frac{1}{1-p_{G}} .
$$

Since $\partial C_{G} / \partial b=(\partial c / \partial b) p_{G}^{\eta_{G}} / \eta_{G}$ and $\partial C_{G}^{2} / \partial p_{G} \partial b=(\partial c / \partial b) p_{G}^{\eta_{G}-1}, \epsilon_{b}=\eta_{G}$. As a result, $\epsilon_{b}>f\left(p_{G}\right)$. Thus, by Proposition 3, short-lived patents are optimal irrespective of the sign of $f\left(p_{G}\right)$. However, the sign of $f\left(p_{G}\right)$ determines the sign of $\partial p_{B}^{*} / \partial T$ and solves the question of whether patent scope should be made broader or narrower to neutralize the effect of shorter patent duration on the incentives to develop new drugs.

\subsection{Implications for Empirical Analysis}

The theoretical model suggests several hypotheses that can be evaluated by merely using data on the generic firms' challenges to new drug patents: First, the model - like other models of costly imitation - predicts that $\partial p_{G}^{*} / \partial T>0$. If $\partial p_{G}^{*} / \partial T>0$ holds in our data, then designing the optimal patent length for the pharmaceutical industry should take into account the additional distortions arising from enhanced incentives for patent challenging.

Second, we determine the sign of $\partial p_{G}^{*} / \partial b$ in our data. Based on the literature, we use multiple measures of patent scope in our empirical analysis. A good measure of patent scope should almost by definition imply that $\partial p_{G}^{*} / \partial b<0$. Furthermore, if $\partial p_{G}^{*} / \partial b<0$ based on some measure of patent scope, then that measure of patent scope could be used neutralize the effect of a change in patent length on incentives to develop new drugs. 
Third, according to our results, the effect of a change in patent length on incentives to develop new drugs depends on the sign of $f\left(p_{G}^{*}\right):=\epsilon_{p}-p_{G}^{*}\left(1-p_{G}^{*}\right)$. Establishing the sign of $f\left(p_{G}^{*}\right)$ also tells whether patent length and scope are substitutable or complementary policy tools. Our data gives a direct estimate of $p_{G}^{*}$. To recover $\epsilon_{p}$, we develop two approaches: one based on the point estimate of $\partial p_{G}^{*} / \partial T$ and another based on the point estimate of $\partial p_{G}^{*} / \partial b$. These point estimates also allow us to assess whether $\epsilon_{b}$ is larger or smaller than $f\left(p_{G}^{*}\right)$, and thereby to complete the characterization of the optimal patent policy.

\section{Construction of Data and Variables}

To characterize optimal patent policy for pharmaceutical industry, we measure generic entry prior to the expiration of new drug patents, and the responses of that entry to changes in effective patent length and in patent scope.

The FDA is our source of the data concerning patents protecting approved new drugs, generic entry before patent expiration, and new drug characteristics. We obtain information on patent attributes from the USPTO and the European Patent Office (EPO). We next explain the construction of variables used in our main regressions. Appendices 2-4 contain further details of our data sources, the dataset development, and the description of variables used in robustness checks.

\subsection{Identifying New Drug Patents}

We construct our sample of new drug patents from 2001 - 2013 annual editions of the Orange Book, which lists patents protecting approved new drugs and their expiration dates. Our sample thus excludes both drug patents that expired before 2001 and patents of drugs whose marketing authorization expired before 2001. For example, the FDA removes obsolete and unexpectedly harmful drugs from the Orange Book (Onakpoya et al., 2016). Truncation of the sample arising from the exclusion of these old patents is unlikely to bias our estimates because generic entry via PIV certifications began to grow only in the late 1990s (see Figure 1).

A more serious truncation bias is likely to stem from the exclusion of patents with long grant lags that were filed at the end of our observation period. Our data may contain fewer of such patents because they were still pending in 2013. To avoid this truncation bias, we only use patents filed before 2009. Our main results are essentially similar without this sample restriction. 
Long grant lags could also cause a reverse distortion at the beginning of our observation period if a patent was filed before 1980, but our data contains only 14 such patents. We drop all patents with grant lags exceeding five years in robustness analyses. Our final sample consists of 3517 new drug patents granted between 1980 - 2013 and listed in the Orange Book.

\subsection{Measuring Generic Entry via Patent Challenges}

Our outcome variable is an indicator for whether a new drug patent listed in the Orange Book has successfully been challenged via PIV certification at least once. In a PIV challenge, a generic firm seeks to enter prior to the expiration of a new drug patent listed in the Orange book by filing an FDA application containing a certification that the new drug patent is invalid, unenforceable, or noninfringed by the generic product (FDA, 2004).

We obtain a list of 1020 approved generic drugs with a PIV certification from the FDA. The list, however, contains no patent information. To identify the successfully challenged new drug patents, we read the FDA's generic drug approval letters. Some of the approval letters are readily available from the Drugs@FDA database. We obtain more approval letters by submitting the Freedom of Information Act requests to the FDA. However, we fail to specify the challenged patents for 343 approved generic drugs with a PIV certification.

Although the missing patent observations may lead to an underestimate of the number of successful PIV challenges at a patent level, the measurement error in our outcome variable, the indicator for at least one successful challenge of a patent via PIV certification, is likely to be small. To measure the outcome variable accurately, it suffices to observe only one of potentially many successful PIV challenges. Moreover, when we aggregate the successful challenges to the active ingredient level, we almost always observe a corresponding challenged patent in our sample. We provide further arguments for why missing patent information is unlikely to bias the results in Appendix 2 .

Figure 1 depicts the number of originator drug patents successfully challenged via PIV certifications in our sample by the generic entry year. If we observe multiple successful PIV challenges of the same new drug patent, we use the one with the earliest generic drug approval date. While using a different measure, Figure 1 confirms the finding documented by Branstetter et al. (2016) that generic entry via PIV certifications became de facto possible only after a series of legal and policy changes at the turn of the millennium. 


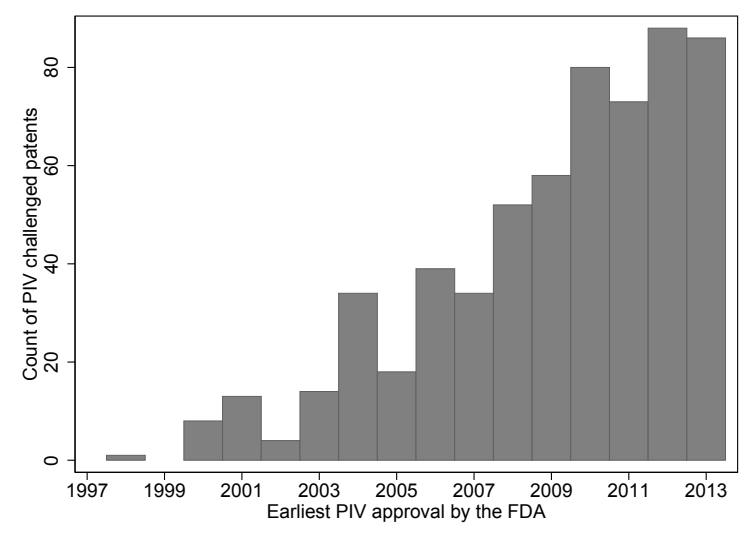

Figure 1: PIV Challenged New Drug Patents.

Notes: The figure shows the number of new drug patents that has successfully been challenged via PIV certifications. In the case of several successful challenges to the same patent, we use the challenge with the earliest approval year.

\subsection{Measuring Effective Patent Length}

The term of a patent can be measured in various ways. Following the model of Section 2, we determine the effective length of a new drug patent- the period when a patent is in force and protects an approved new drug. To calculate this effective length, we subtract from the expiration date of a patent either its grant date or the approval date of a drug protected by this patent, whichever occurs later. If a patent protects several new drugs, we use the first of their approval dates. We use the USPTO Patent Examination Research Dataset (PatEx) to determine patent grant dates and the Orange Book to identify the patent expiration and new drug approval dates.

This effective patent length varies for three reasons. First, its starting date depends on whether the FDA drug approval or the USPTO patent grant comes later. Second, legal reforms changed the standard patent term in the US during our observation period. Third, patent-specific term extensions and adjustments partially compensate for both the FDA and USPTO lags. We explain these patent term reforms and USPTO term adjustments in Section 5.1.

Starting dates based on drug approval and compensations for the FDA approval lags make some variation in the effective length specific to new drug patents. However, the USPTO grant lags may also affect the effective length even if it runs from the FDA approval date. For example, originator firms may want to ensure the possession of core patents even before entering clinical trials (see, e.g., Fernandez and Huie, 2003; Budish et al., 2015). 


\subsection{Measuring Patent Scope}

There are many different measures of patent scope (breadth). We identify several measures of patent claim scope from the USPTO Patent Claims Research Dataset. We calculate the count of "Markus groups" in the first independent claim. Drug patent claims often include such Markush groups - lists of functionally equivalent alternatives (see, e.g., Kuhn and Thompson, 2019). The count of Markush groups in the first independent claim of a patent might reflect different potential uses of the drug protected by the patent, and hence its scope. A common and acceptable form of a Markush group is "...selected from the group consisting of $A, B$, and $C . "{ }^{4}$ We thus use the count of the phrase "selected from" in the first independent claim as a proxy for the count of Markush groups. (We get similar results if we use the phrase "consisting of" as a proxy for a Markush group).

We also calculate the count of "or" in the first independent claim, since the coordinating conjunction "or" might be used to introduce variants or different elements of the drug protected by the patent. In addition, we calculate the count of words in the first independent claim. Some studies (e.g., Okada et al., 2016; Kuhn and Thompson, 2019; Marco et al., 2019) use the number of words in claims as an inverse proxy for patent scope. However, Kuhn and Thompson (2019) argue that the use of Markush groups reverses this inverse relationship between claim length and scope in the case of pharmaceutical patents. Following, e.g., Lanjouw and Schankerman (2001, 2004) and Marco et al. (2019), we also use the number of independent claims as a proxy for patent scope.

Measures of patent claim scope are frequently used in the literature since they are easy to construct and their legal foundations are clear: the purpose of patent claims is to set out "the metes and bounds" of the patent rights (e.g., Merges and Nelson, 1990 and Freilich, 2015). In our case, another advantage of claim scope measures is that we can formulate patent-examiner specific instruments in an attempt to identify the effects of patent scope on PIV patent challenges (see Section 6). Yet, measures of claim scope are at best imperfect proxies for patent scope and, at worst, it is ambiguous whether a change in a claim scope measure (e.g., an additional claim or word) makes a patent broader or narrower. We thus also seek alternative proxies for patent scope.

Using the Orange Book, we create dummies measuring whether or not a patent in our sample protects a drug with new chemical entity (NCE), orphan drug, or pediatric exclusivity. These

\footnotetext{
${ }^{4}$ See, e.g., the USPTO Manual of Patent Examining Procedure ( $9^{\text {th }}$ edition) $\S 803.02$, https://www.uspto.gov/ web/offices/pac/mpep/s803.html\#d0e98237, last accessed on February 5, 2020.
} 
exclusivities are granted by the FDA upon approval of the drug, and they prevent generic companies from using clinical trials data from the original products, making generic entry all but prohibitively costly during the exclusivity period (see, e.g., Yin, 2017). NCE exclusivity last four to five years, and orphan drug exclusivity seven years. These exclusivities thus should make a drug patent stronger compared to patents with no exclusivity or with the three year clinical investigation exclusivity. Pediatric drugs may get six months of exclusivity on the top of other exclusivity periods and the patent term. Pediatric exclusivity thus makes patent protection both broader and longer.

Finally, we create dummies measuring whether a patent in our data covers an active ingredient, a method of use, or some other pharmaceutical invention (e.g., drug formulation or composition). Active ingredient patents might provide stronger protection than other types of new drug patents (Hemphill and Sampat, 2011b). As detailed in Appendix 2, we infer these patent properties from the abstracts and claims of patents by using text pattern recognition algorithm and manual verification.

\subsection{Other Patent Characteristics}

We control for several characteristics of our sample patents and of the drugs protected by those patents. We determine from the Orange Book whether a patent protects a drug that is available as a capsule, an injection, a tablet or in some other, less common form. A dosage form may affect generic firms' incentives to engage in PIV challenges, since some dosage forms may be easier, e.g., to manufacture or to distribute to consumers, or to use by consumers. From the Drugs@FDA database, we identify whether a patent protects a drug priority reviewed by the FDA. Such priority reviews may reflect drug value.

We collect data on backward and forward patent citations from the USPTO Patent Full-Text and Image Database (PatFT), and on patent family size from the Open Patent Services of the EPO. Patent family size and citations are commonly used indicators of patent value (Lanjouw and Schankerman, 2004; Gambardella et al., 2008). Backward citations could also serve as proxy for patent scope: for example, careful documentation of prior art can make a patent difficult to invalidate on the grounds of failure to disclose prior art (Lanjouw and Schankerman, 2001; Harhoff and Reitzig, 2004). However, a high number of backward citations may also indicate a patent protecting an incremental invention, which could make the patent less lucrative for PIV challenges.

From PatEx, we identify patents filed as continuation, continuation-in-part or divisional appli- 
cations. Such "continuing patents" may differ from other patents across various dimensions (Lemley and Moore, 2004) that may affect propensity to encounter PIV challenges.

We retrieve the main three-digit U.S. Patent Classification (USPC) number and the filing year of each patent in our sample from PatEx, and use them as fixed effects to control for technology specific idiosyncrasies and time trends in patenting. To account for possible negative bias in our length estimates due to different exclusivity periods, we construct fixed effects for the latest exclusivity expiration year (obtained from the Orange Book). ${ }^{5}$ To cluster the regression standard errors, we identify from the Orange Book the first FDA-approved active ingredient related to each patent.

\subsection{Summary Statistics}

Table 1 reports the summary statistics for our sample of 3517 new drug patents. Over 17 percent of these patents have been successfully challenged by generic firms via PIV certifications. The effective length of pharmaceutical patents is on average almost 13 years, varying from one month to 20 years.

A new drug patent has three independent claims on average. An average first independent claim contains one Markush group and 117 words of which three are the conjunction "or". The average numbers of backward and forward citations are both roughly around 35, and the mean patent family size is 13. All count variables have highly skewed distributions.

Half of the patents in our sample protect a drug covered by either NCE exclusivity or orphan drug exclusivity. Furthermore, pediatric exclusivity is attached to 18 percent of the patents. Approximately 23 percent of the patents concern active ingredients and 31 percent concern new methods of use. A majority of the patents are filed as continuing applications. Around 20 percent of the patents protect injectable drugs, 16 percent capsules, 38 percent tablets, and around eight percent protect drugs priority reviewed by the FDA.

\footnotetext{
${ }^{5}$ When constructing these fixed effects for the latest exclusivity expiration year, we group together patents protecting a drug for which we observe no exclusivity. This group includes both drugs for which the FDA never awarded exclusivity and drugs whose exclusivity expired before 2001 (the beginning of our observation period). Our results remain similar when estimated using the sample of patents protecting drugs for which we observe exclusivity (see Table 7 in Appendix A.3).
} 
Table 1: Summary Statistics for New Drug Patents.

\begin{tabular}{lccccc}
\hline \hline & Mean & Std. Dev. & Min & Max & N \\
\hline PIV entry & 0.171 & 0.377 & 0 & 1 & 3517 \\
Effective length & 12.586 & 3.931 & 0.096 & 20 & 3517 \\
Markush groups & 0.704 & 4.151 & 0 & 112 & 3485 \\
Conjuctions "or" & 3.256 & 9.572 & 0 & 184 & 3485 \\
Words & 116.890 & 153.337 & 1 & 2197 & 3485 \\
Independent claims & 3.187 & 3.840 & 1 & 92 & 3488 \\
NCE exclusivity & 0.374 & 0.484 & 0 & 1 & 3517 \\
Orphan drug exclusivity & 0.123 & 0.328 & 0 & 1 & 3517 \\
Pediatric exclusivity & 0.177 & 0.382 & 0 & 1 & 3517 \\
Method patent & 0.311 & 0.463 & 0 & 1 & 3517 \\
Active ingredient patent & 0.226 & 0.419 & 0 & 1 & 3517 \\
Forward citations & 35.705 & 57.889 & 0 & 1297 & 3517 \\
Backward citations & 34.065 & 63.209 & 0 & 1005 & 3517 \\
Patent family size & 13.418 & 12.031 & 1 & 51 & 3511 \\
Continuing patent & 0.589 & 0.492 & 0 & 1 & 3517 \\
Priority review & 0.078 & 0.269 & 0 & 1 & 3517 \\
Tablet & 0.384 & 0.486 & 0 & 1 & 3517 \\
Capsule & 0.160 & 0.366 & 0 & 1 & 3517 \\
Injectable & 0.195 & 0.397 & 0 & 1 & 3517 \\
\hline
\end{tabular}

Notes: This table reports summary statistics for our sample of 3517 new drug patents. PIV entry equals 0 if a patent has never been successfully challenged via a PIV certification, and 1 otherwise. Effective length is measured in years and defined as "Expiration date - $\max \{$ Grant date, Drug approval date $\}$ ". The third, fourth and fifth row depict the counts of Markush groups, conjunctions "or", and words, respectively, in the first independent claim. Each exclusivity indicator equals 1 if a patent covers a drug that has been awarded the corresponding exclusivity. The indicators Method patent and Active ingredient patent equal 1 if a patent protects a method of use and an active ingredient, respectively. The indicators Tablet, Capsule, and Injectable equal 1 if the drug protected by a patent has the corresponding dosage form. The Priority review indicator equals 1 if a patent has been priority reviewed by the FDA, and the Continuing patent indicator equals 1 if a patent is filed as a continuation, a continuation-in-part or a divisional application. Independent claims, Backward citations, Forward citations, and Patent family size give the count of independent claims included in a patent in our sample, of earlier patents cited by a patent in our sample, of later patents citing a patent in our sample, and of countries where the same new drug has been patented, respectively. 


\section{Evidence from Ordinary Least Squares Regressions}

We begin by estimating the following OLS regression using our patent-level data:

$$
\mathbb{1}\left(\mathrm{PIV} \mathrm{entry}_{i t}\right)=\alpha+\beta \log \left(\text { Effective length }_{i}\right)+\gamma^{\prime} \mathbf{X}_{\mathbf{i}}+\delta_{t}+\eta_{i t},
$$

in which $\mathbb{1}\left(\mathrm{PIV}\right.$ entry $\left._{i t}\right)$ is an indicator variable equaling one if patent $i$ filed in year $t$ is successfully

challenged via a PIV certification, $\log \left(\right.$ Effective length $\left._{i}\right)$ is the natural logarithm of the effective length of patent $i$, the vector $\mathbf{X}_{\mathbf{i}}$ includes other controls except for the patent filing year fixed effects captured by $\delta_{t}$. Table 2 presents estimates from various specifications of the model. 
Table 2: PIV Entry and Patent Characteristics: OLS Estimates.

\begin{tabular}{|c|c|c|c|}
\hline & (1) & $(2)$ & $(3)$ \\
\hline $\log ($ Effective length $)$ & $\begin{array}{c}0.129^{* * *} \\
(0.015)\end{array}$ & $\begin{array}{c}0.069^{* * *} \\
(0.013)\end{array}$ & $\begin{array}{c}0.065^{* * *} \\
(0.013)\end{array}$ \\
\hline NCE exclusivity & & $\begin{array}{c}-0.091^{* * *} \\
(0.025)\end{array}$ & $\begin{array}{c}-0.075^{* * *} \\
(0.026)\end{array}$ \\
\hline Orphan drug exclusivity & & $\begin{array}{c}-0.093^{* * *} \\
(0.024)\end{array}$ & $\begin{array}{c}-0.092^{* * *} \\
(0.025)\end{array}$ \\
\hline Pediatric exclusivity & & $\begin{array}{c}0.087^{* *} \\
(0.035)\end{array}$ & $\begin{array}{c}0.086^{* *} \\
(0.035)\end{array}$ \\
\hline Priority review & & $\begin{array}{c}0.179^{* * *} \\
(0.046)\end{array}$ & $\begin{array}{c}0.178^{* * *} \\
(0.047)\end{array}$ \\
\hline Tablet & & $\begin{array}{c}0.181^{* * *} \\
(0.027)\end{array}$ & $\begin{array}{c}0.183^{* * *} \\
(0.028)\end{array}$ \\
\hline Capsule & & $\begin{array}{c}0.106^{* * *} \\
(0.034)\end{array}$ & $\begin{array}{c}0.112^{* * *} \\
(0.035)\end{array}$ \\
\hline Injectable & & $\begin{array}{l}-0.041^{*} \\
(0.024)\end{array}$ & $\begin{array}{l}-0.033 \\
(0.024)\end{array}$ \\
\hline $\log ($ Markush groups +1$)$ & & & $\begin{array}{l}-0.012 \\
(0.012)\end{array}$ \\
\hline Method patent & & & $\begin{array}{l}-0.029^{*} \\
(0.017)\end{array}$ \\
\hline Active ingredient patent & & & $\begin{array}{c}-0.063^{* * *} \\
(0.021)\end{array}$ \\
\hline $\log ($ Forward citations +1$)$ & & & $\begin{array}{c}0.003 \\
(0.007)\end{array}$ \\
\hline $\log ($ Backward citations +1$)$ & & & $\begin{array}{c}-0.021^{* *} \\
(0.008)\end{array}$ \\
\hline $\log ($ Patent family size $)$ & & & $\begin{array}{l}0.010^{*} \\
(0.006)\end{array}$ \\
\hline Continuing patent & & & $\begin{array}{c}0.024 \\
(0.015)\end{array}$ \\
\hline Mean dep. variable & 0.171 & 0.171 & 0.173 \\
\hline Observations & 3517 & 3517 & 3483 \\
\hline R-squared & 0.065 & 0.224 & 0.237 \\
\hline Filing year FE & $\times$ & $x$ & $\times$ \\
\hline Exclusivity expiration year FE & & $x$ & $\times$ \\
\hline USPC FE & & & $x$ \\
\hline
\end{tabular}

We find a statistically significant but economically modest relationship between PIV entry and 
the effective patent length. The estimated coefficient in column (1) implies that doubling the effective term of a patent is associated with a 13 percentage point increase in the probability of PIV entry. The relationship becomes economically weaker but continues to be statistically significant after adding various controls, as shown by columns (2) and (3) of Table 2.

Table 2 indicates a possible negative, but statistically insignificant, relationship between PIV entry and the count of Markush groups in the first independent claim. (As shown in Table 8 in Appendix A.4, using another measures of patent claim scope instead of the count of Markus groups yields similar results, except that the logged count of conjunctions "or" in the first independent claim gets a negative and statistically significant coefficient.) Estimates for the other measures of scope, however, suggest stronger associations: The probability of PIV entry is over six percentage points lower for patents covering active ingredients, and three percentage points lower for patents covering new methods of use compared to patents protecting, say, new drug formulations. Furthermore, the probability of PIV entry is around eight to nine percentage points lower for patents protecting drugs with NCE or orphan drug exclusivity. Pediatric exclusivity appears to be associated with an increase in the rate of PIV entry. However, pediatric exclusivity not only provides broader protection, but also lengthens the patent term.

The negative estimate of the effect of backward citations might also support a negative association between PIV entry and patent scope, but it could also suggest a positive association between PIV entry and patent value. This positive association between PIV entry and patent value is also supported by the positive and statistically significant coefficients of $\log \left(\right.$ Patent familiy size $\left._{i}\right)$ and the dummy variables Priority review $i$, Tablet $i$, and Capsule ${ }_{i}$.

Overall the findings from the OLS regressions suggest that PIV entry positively correlates with effective patent length and negatively with patent scope. However, while we attempt to control for, e.g., drug and patent value, these results may still be driven by unobserved heterogeneity.

\section{Impact of Patent Length}

In Section 5.1, we describe how two patent policy reforms, TRIPS of 1994 and AIPA of 1999, affected the effective lengths of patents depending on their grant lags. Using this plausibly exogenous variation in effective length across patents and over time, we estimate the effects of the reforms on the probability of PIV entry in Section 5.2. 


\subsection{Patent Term Reforms in the US and Pharmaceutical Patents}

TRIPS introduced a 20-year standard patent term measured from the (earliest) filing date to the US. Prior to TRIPS, the US had a 17-year standard patent term counting from the grant date. The change in the standard patent term was implemented so that the 20-year term from filing applies to the patents filed on and after June 8, 1995. For patents filed prior to June 8, 1995, the standard patent term was changed to either the new 20-year term from filing or the old 17-year term from the grant, whichever expires later. (Patents that were issued prior to June 8, 1978, were kept in the old 17-year term regime, but our sample includes no such old patents.)

This change in the standard patent term due to TRIPS treats patents differently depending on whether or not they are granted within three years from filing: Patents granted within three years from filing receive the same 20-year standard term from filing regardless of whether or not they are filed before or after TRIPS (came into force). In contrast, patents with grant lags exceeding three years filed before TRIPS received the 17-year standard term from the grant date, which fully compensates for grant lags. But similar patents filed after TRIPS receive the 20-year standard term from filing, thus losing some of effective protection time because of TRIPS.

To compensate patentees for this loss in effective patent life because of delays in the USPTO approval process, TRIPS also introduced PTAs (which were initially called patent term extensions). These PTAs only apply to patents filed after TRIPS, and can add a maximum of five years to the patent term. The USPTO calculates the length of a PTA automatically, taking into account only certain delays caused by the USPTO itself. Initially eligible delays were limited (to interference, secrecy orders, successful appeals to the Patent Trial and Appeal Board or to the federal courts) but, subsequently, AIPA expanded the list of reasons which may give rise to PTAs for patents filed on and after May 29, 2000. In particular, AIPA introduced compensation for grant lags exceeding three years, thus at least partially neutralizing the adverse impact of TRIPS on the length of patents with grant lags exceeding three years.

We determine PTAs and grant lags for our sample of drug patents from PatEx. As shown by panels A and B of Figure 2, PTAs were rare and their duration was short before AIPA (came into force), which increased their provision substantially. The share of patents with a PTA rises from two percent in 1996 to 66 percent in 2005 in our sample (panel A). The average PTA length increases from less than a month in 1996 to around 15 months in 2005 (panel B). Even after AIPA, the 
increase in the length of PTAs was gradual, reflecting increasingly slow patent prosecution at the USPTO in the early years of the millenium (panel C). (The long grant lags observed in the early years in panel $\mathrm{C}$ are a consequence of the truncation of our sample discussed in Section 3.1).

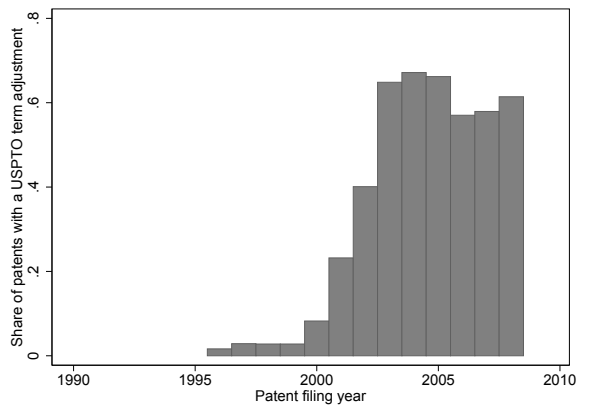

A Share of Patents with a USPTO PTA

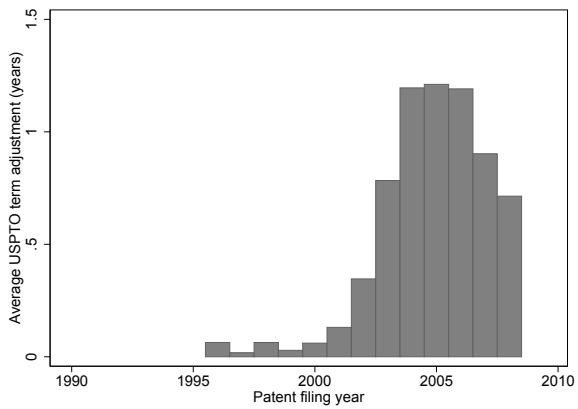

B Average PTA Length

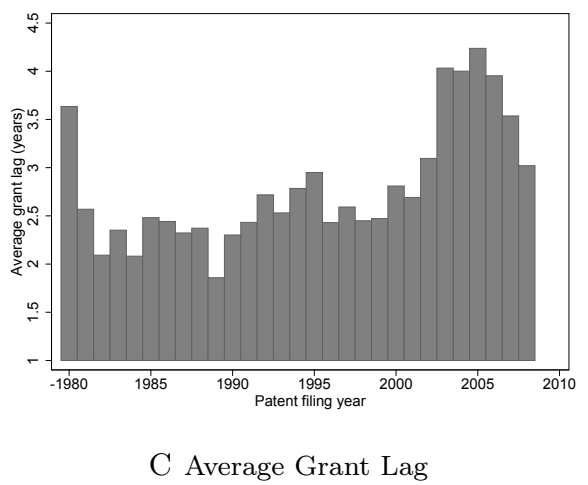

Figure 2: USPTO Grant Lags and PTAs of Pharmaceutical Patents.

Notes: Panel A of this figure shows the share of new drug patents in our sample with a USPTO PTA by patent filing year. Panel B shows the average length of a PTA in our sample by patent filing year, including patents without PTAs. Panel C figure shows the average grant lag of new drug patents in our sample by patent filing year.

Comparing panels $\mathrm{A}$ and $\mathrm{B}$ with panel $\mathrm{C}$ indicates that PTAs fail to fully compensate for the adverse impact of TRIPS on the effective length of new drug patents with long grant lags, especially before AIPA. To confirm this suggestion, we regress the patent grant lag on the effective patent length separately for the periods of pre-TRIPS, post-TRIPS but pre-AIPA, and post-AIPA. Figure 3 shows the results: Before TRIPS, the effective length is relatively invariant to the grant lag. TRIPS disproportionately shortens the effective length of patents that were pending more than three years, especially before AIPA, which partially restores the effective length of such patents. 


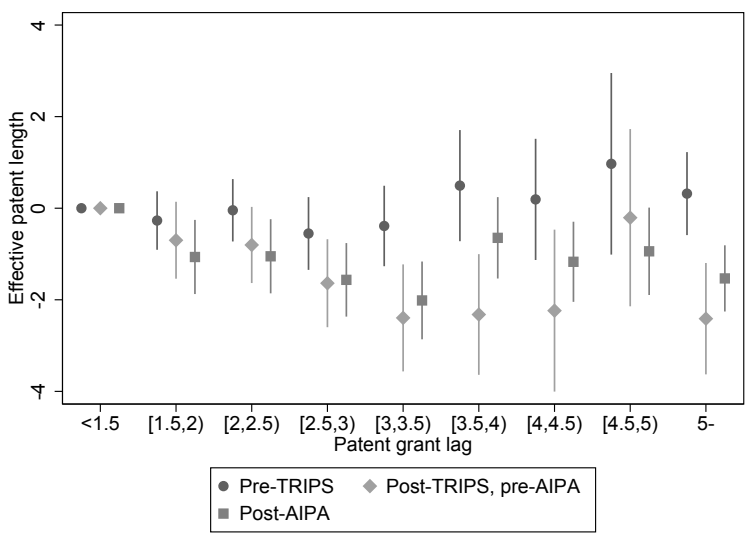

Figure 3: Effective Patent Length Before and After TRIPS and AIPA.

Notes: This figure shows relationships between the patent grant lag (in the $x$-axes) and the effective patent length (in the $y$-axis). We estimate the relationships separately for three time periods by using OLS and our patent-level data. The pre-TRIPS period includes patents filed before June 8, 1995. The pre-TRIPS, post-AIPA period includes patents filed between June 8, 1995 and May 29, 2000. The post-AIPA period includes patents filed on or after May 29, 2000. In each regression, the comparison group consists of patents granted less than 1.5 years from the filing date. Each dot shows the averages of the $x$ - and $y$-axes variables within each equal-sized bin.

\subsection{Difference-in-Differences Estimations and Results}

In Section 5.1 we document how patents with grant lags exceeding three years have shorter effective lengths than other patents after TRIPS. The model of Section 2 predicts an increase in the rate of PIV entry encountered by such patents after TRIPS. Furthermore, this positive effect of TRIPS on the rate of PIV entry should be stronger before AIPA than after it. Consistent with this prediction, Figure 4 indicates that in the post-TRIPS, pre-AIPA period, the rate of PIV entry is lower for patents prosecuted over three years compared to patents with shorter grant lags. There is no similar difference between the two patent groups in other periods. These patterns in grant lags and PIV entry motivate our research design. 


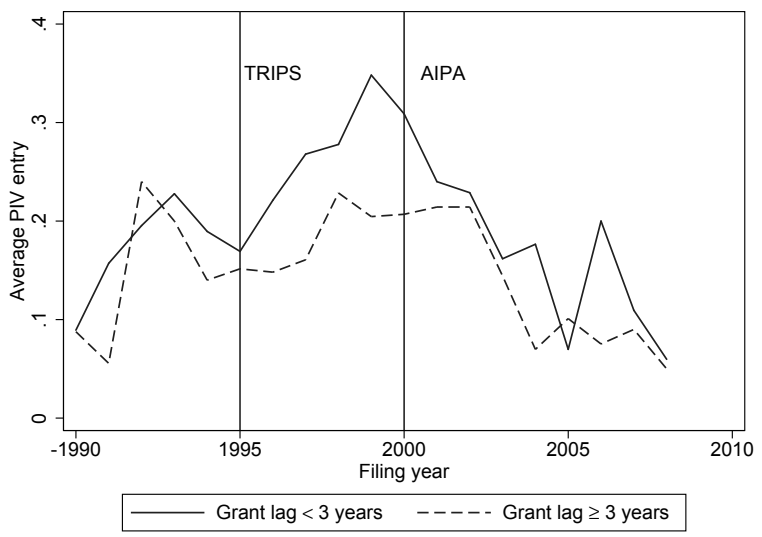

Figure 4: Average PIV Entry by Patent Filing Year and Grant Lag.

Notes: This figure shows the average PIV entry by patent filing year. The dashed and solid lines depict the groups of patents with a grant lag more and less than three years, respectively. The year 1990 also includes all patents filed before it. Those oldest patents in our sample encounter only few successful PIV challenges with no systematic difference depending on the grant lag.

We estimate the following DiD model using our patent-level data:

$$
\begin{aligned}
& \mathbb{1}\left(\mathrm{PIV} \text { entry }_{i t}\right)=\alpha+\beta_{1} \mathbb{1}\left({\text { Grant } \left.\operatorname{lag}_{i} \geq 3 \text { years }\right)+}\right)
\end{aligned}
$$

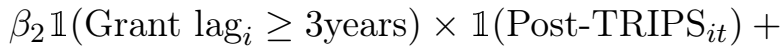

$$
\begin{aligned}
& \beta_{3} \mathbb{1}\left(\text { Grant } \operatorname{lag}_{i} \geq 3 \text { years }\right) \times \mathbb{1}\left(\text { Post-AIPA }_{i t}\right)+\gamma^{\prime} \mathbf{X}_{\mathbf{i}}+\delta_{t}+\varepsilon_{i t},
\end{aligned}
$$

in which $\mathbb{1}$ (Grant $\operatorname{lag}_{i} \geq 3$ years) is an indicator variable equaling one if patent $i$ filed in year $t$ has at least a three-year grant lag, $\mathbb{1}\left(\right.$ Post-TRIPS $\left._{i t}\right)$ is an indicator variable equaling one if the filing date of patent $i$ is on or after June 8, 1995, and $\mathbb{1}\left(\right.$ Post-AIPA $\left._{i t}\right)$ is an indicator variable equaling one if the filing date of patent $i$ is on or after May 29, 2000. The coefficients of interest, $\beta_{2}$ and $\beta_{3}$, measure changes in the probability of PIV entry after TRIPS and AIPA, respectively, for patents prosecuted at least three years (treatment group), compared to other patents (control group). 
Table 3: PIV Entry, Effective Length, and Patent Law Changes by Patent Grant Lag.

\begin{tabular}{lcccccc}
\hline \hline Outcome & $\begin{array}{c}\text { PIV } \\
\text { entry } \\
(1)\end{array}$ & $\begin{array}{c}\text { PIV } \\
\text { entry } \\
(2)\end{array}$ & $\begin{array}{c}\text { PIV } \\
\text { entry } \\
(3)\end{array}$ & $\begin{array}{c}\text { PIV } \\
\text { entry } \\
(4)\end{array}$ & $\begin{array}{c}\text { PIV } \\
\text { entry } \\
(5)\end{array}$ & $\begin{array}{c}\text { log(Effective } \\
\text { length) } \\
(6)\end{array}$ \\
\hline Grant lag $\geq 3$ years & -0.021 & 0.016 & 0.026 & 0.021 & 0.022 & 0.044 \\
& $(0.027)$ & $(0.025)$ & $(0.025)$ & $(0.026)$ & $(0.028)$ & $(0.028)$ \\
Grant lag $\geq 3$ years, & & & & & & \\
Post-TRIPS & $-0.080^{*}$ & $-0.114^{* * *}$ & $-0.106^{* * *}$ & $-0.099^{* *}$ & $-0.100^{* *}$ & $-0.171^{* * *}$ \\
& $(0.042)$ & $(0.039)$ & $(0.039)$ & $(0.044)$ & $(0.041)$ & $(0.043)$ \\
Grant lag $\geq 3$ years, & & & & & & \\
Post-AIPA & $0.072^{*}$ & $0.084^{* *}$ & $0.072^{*}$ & 0.066 & $0.072^{*}$ & $0.100^{* *}$ \\
& $(0.041)$ & $(0.037)$ & $(0.037)$ & $(0.042)$ & $(0.039)$ & $(0.045)$ \\
\hline Mean dependent variable & 0.171 & 0.171 & 0.173 & 0.167 & 0.177 & 2.457 \\
Observations & 3517 & 3517 & 3483 & 2998 & 3066 & 3517 \\
R-squared & 0.045 & 0.221 & 0.234 & 0.234 & 0.240 & 0.020 \\
\hline Filing year FE & $\times$ & $\times$ & $\times$ & $\times$ & $\times$ & $\times$ \\
Drug controls & & $\times$ & $\times$ & $\times$ & $\times$ & \\
Exclusivity expiration year FE & & $\times$ & $\times$ & $\times$ & $\times$ & \\
Patent controls & & & $\times$ & $\times$ & $\times$ & None \\
USPC FE & & & $\times$ & $\times$ & $\times$ & Any \\
Excluded filing years & None & None & None & 1995, & None & Any \\
Grant lag & & Any & Any & Any & $\leq 5$ yrs & Any
\end{tabular}

Notes: This table reports estimates of the effects of TRIPS and AIPA on PIV entry and the effective patent length. Columns (1)-(5) show coefficients from an OLS regression of the PIV entry indicator and column (6) of $\log ($ Effective length) on three different indicators for patents with at least a three-year grant lag and controls. FE stands for fixed effects. Drug controls include the indicators New chemical exclusivity, Orphan drug exclusivity, Pediatric exclusivity, Priority review, Capsule, Injectable, and Tablet. Patent controls include $\log$ (Markush groups +1$), \log ($ Backward citations +1$), \log$ (Forward citations +1$), \log ($ Patent family size), and the indicators Active ingredient patent, Method patent, and Continuing patent. In column (4) the sample excludes patents filed in years 1995 and 2000 and in column (5) the sample excludes patents with a grant lag exceeding five years. Standard errors, in parentheses, are clustered at the level of patents protecting the same active ingredient. ${ }^{*} p<0.10,{ }^{* *} p<0.05,{ }^{* * *} p<0.01$.

Column (1) of Table 3 reports coefficients from a regression that uses the full sample of new drug patents but only controls for filing year fixed effects. Patents prosecuted at least three years experience an eight percentage point reduction in the probability of PIV entry after TRIPS (but before AIPA), compared to other patents. AIPA partially neutralizes this effect: the corresponding increase in the probability of PIV entry is seven percentage points after AIPA.

Column (2) of Table 3 reports results after we add characteristics of the drugs protected by the patents in our sample, including exclusivities and their expiration year fixed effects. Column (3) shows results from a specification that further controls for patent characteristics, including 
the main US patent class fixed effects. These two specifications attempt to account for potential differences between the treatment and control groups stemming from observable characteristics, unobserved heterogeneity, and possible compositional changes over time across these groups. Adding the fixed effects and other controls makes the effects of TRIPS and AIPA stronger and more precisely estimated compared to column (1).

We also estimate equation (19) using a sample that excludes patents filed in 1995 and 2000. This sample restriction attempts to address the potential bias arising from anticipation of the TRIPS and AIPA reforms. For example, applicants expecting a decrease in patent terms due to TRIPS could have advanced patent filing and, analogously, applicants expecting an increase in patent terms due to AIPA could have postponed filing. The coefficient estimates from this regression, reported in column (4) of Table 3, remain similar to the baseline estimates, suggesting no clear anticipation effects. The coefficient $\beta_{3}$ is, however, less precisely estimated, perhaps due to a smaller sample.

Next, we estimate the DiD model of equation (19) using a sample of patents prosecuted within five years. This sample restriction further mitigates the concerns arising from possible compositional changes in the treatment group. For example, exceptionally long grant lags observed in the earliest and the latest years of our data increase the number of patents falling into the treatment group (see panel $\mathrm{C}$ of Figure 2). This restriction also excludes the patents for which the five-year maximum length of PTAs is binding. The results from this estimation reported in column (5) are similar to the baseline results.

To measure the effect of TRIPS and AIPA on the effective patent length, we also estimate an analogous DiD model to equation (19) in which we replace $\mathbb{1}\left(\mathrm{PIV}\right.$ entry $\left.{ }_{i t}\right)$ by $\log \left(\mathrm{Effective} \mathrm{patent} \mathrm{length}_{i}\right)$ as an outcome variable. The results reported in column (6) of Table 3 show that patents prosecuted at least three years experience a 17 percent decrease in their effective term after TRIPS, compared with other patents. After AIPA the effective length of these patents increases by 10 percent.

Robustness. Overall, we find that the probability of PIV entry increases with effective patent length, as predicted by the theory: TRIPS shortens the effective length of patents with long grant lags, and this shortened effective length discourages PIV entry, whereas AIPA partially restores the effective length of those patents which promotes PIV entry.

To assess the robustness of these findings, we make a number of further checks, some of which are detailed in Appendix A.3. There we show that the estimated effects on the probability of PIV 
entry cannot be explained by differential changes in patent scope or value after TRIPS and AIPA, nor by the introduction of provisional applications in 1995. When we estimate equation (19) using different subsamples and specifications, the effects of TRIPS and AIPA only become stronger and more precisely estimated.

We find additional evidence of longer effective patent length encouraging PIV entry: TRIPS disproportionately shortened effective terms of continuing patents, leading to a more negative estimate of $\beta_{2}$ using the sample of these patents. Finally, we document how AIPA also mandated earlier disclosure of patent applications, resulting in a longer period of public patent applications. This change may affect the interpretation of the effective patent length in the post-AIPA period.

\section{Impact of Patent Scope}

In identifying the effect of a change in patent scope on PIV patent challenges we cannot resort to an ideal experiment in which some patents are randomly assigned broader protection than other patents. Inspired by Kuhn and Thompson (2019), Sampat and Williams (2019), and Farre-Mensa et al. (2020), we instead develop IVs for patent scope based on the "leniency" of patent examiners. Our approach exploits the differences across examiners in their propensity to grant broader or more claims as a source of variation in patent scope, together with the assignment of patent applications to examiners at the USPTO. Previous research (e.g., Cockburn et al., 2003; Lemley and Sampat, 2012) indicates that examiners differ in their decision making which translates into different patent outcomes. Since patent prosecution typically consists of several rounds of claim rejections and modifications required by an examiner (Kuhn and Thompson, 2019; Marco et al., 2019), systematic differences across examiners plausibly generate systematic differences in patent claim scope.

The second stage of our two-stage least squares (2SLS) analysis consists of estimations of equation (18) using instrumented scope measures. We instrument the following four measures of scope of a new drug patent: the counts of Markush groups, the coordination conjunctions "or", and words in the first independent claim, and the count of independent claims. (Kuhn and Thompson, 2019, too, develop a similar IV for the count of words in the first independent claim.) For each scope measure $x_{i j t}$ of new drug patent $i$ reviewed by examiner $j$ and filed in year $t$, we construct the corresponding instrument $z_{i j t}$ as 


$$
z_{i j t}=\frac{\sum_{\tau=\underline{\tau}_{j}}^{t-1} \sum_{k=1}^{n_{j \tau}} x_{k j \tau}}{\sum_{\tau=\underline{\tau}_{j}}^{t-1} n_{j \tau}},
$$

in which $x_{k j \tau}$ is the scope measure of (any type of) patent $k$ reviewed by examiner $j$ and filed in year $\tau, n_{j \tau}$ denotes the number of patents reviewed by examiner $j$ in filing year $\tau$, and $\underline{\tau}_{j}$ denotes the earliest filing year of any patent reviewed by examiner $j$. Hence, $z_{i j t}$ gives the "examiner $j$ 's historical average" - the cumulative average of a scope measure over all patents assigned to examiner $j$ up to one year preceding the filing year of new drug patent $i .^{6}$

Table 4 shows marked variation across the examiners of the new drug patents in our sample in granting broader or more claims. For example, the average number of words in the first independent claim is 147 , but the toughest examiner only allows 11 words on average, whereas the most lenient examiner allows 456 words on average. This variation unlikely arises from a small sample size: as shown in the last row of Table 4, the average number of patents reviewed by an examiner is 626

Table 4: Heterogeneity Across Examiners in Patent Measures.

\begin{tabular}{lcccc}
\hline \hline & Mean & Std. Dev. & Min & Max \\
\hline Examiner average of Markush groups & 0.786 & 1.037 & 0.000 & 7.000 \\
Examiner average of conjunctions "or" & 3.633 & 4.100 & 0.000 & 21.737 \\
Examiner average of words & 147.115 & 59.068 & 11.000 & 455.776 \\
Examiner average of independent claims & 2.397 & 0.443 & 1.000 & 4.455 \\
Patents reviewed by an examiner & 625.515 & 660.926 & 1 & 3653 \\
\hline
\end{tabular}

Notes: This table reports summary statistics for 579 examiners who have reviewed the new drug patents in our sample. Each of the first four rows shows summary statistics for a examiner-specific patent scope measure, averaging over all patents reviewed by an examiner of a new drug patent in our sample. The last row shows summary statistics for the number of patents reviewed by an examiner of a new drug patent in our sample.

In the first-stage of our 2SLS analysis, we regress each of the four claim scope measures on the corresponding instrument and controls. In the main 2SLS specifications we use the same control variables as in column (3) of Table (2). While some of these controls (e.g., patent filing year and US

\footnotetext{
${ }^{6}$ As shown by equation (20), $z_{i j t}$ includes also all new drug patents reviewed by examiner $j$, filed before year $t$, but excludes all patents reviewed by examiner $j$ for $\tau=t, t+1, \ldots, \bar{\tau}_{j}$, in which $\bar{\tau}_{j}$ is the last filing year of any patent reviewed by examiner $j$. We obtain similar results by excluding all new drug patents reviewed by examiner $j$ from $z_{i j t}$, or by allowing $\tau$ to run from $\underline{\tau}_{j}$ to $\min \left\{\bar{\tau}_{j}, 2009\right\}$ and only imposing $k \neq i$ in equation (20). Although we include the previous new drug patents granted by an examiner in our instrument, we exclude their granted parents and continuations because they are usually assigned to the same examiner (Righi and Simcoe, 2019).
} 
patent class fixed effects) may also capture examiner specialization, we also add USPTO Technology Center fixed effects. Technology Centers are responsible for examination in broad technological areas. Each Technology Center typically contains a few dozen Art Units, which are groups of examiners specializing in narrow technology areas. Within a Technology Center, a patent application is assigned to an Art Unit and finally to an examiner. We use Technology Center fixed effects instead of Art Unit fixed effects because we only observe a small number of (eventually granted) new drug patents per Art Unit.

The exclusion restriction in our setting holds if, conditional on covariates, examiners' propensity to grant broader claims is uncorrelated with such application characteristics, e.g., drug or patent value or quality, that correlate with PIV entry. The validity of this exclusion restriction is supported by the evidence in, e.g., Lemley and Sampat (2012), Sampat and Williams (2019), Kuhn and Thompson (2019), and Farre-Mensa et al. (2020), although, e.g., Righi and Simcoe (2019) are more critical. These previous studies indicate that examiner assignment is independent of application characteristics at the time of filing. For example, examiner assignment is based on the last digit of the application number in Art Units. Such assignment plausibly implies that examiner characteristics are uncorrelated with the value or quality of applications. While Righi and Simcoe (2019) show that examiners specialize in narrow technology fields, they find no evidence that more valuable or broader applications are allocated to certain examiners. Moreover, since our new drug patents form a homogeneous technology field, examiners are less likely to be specialized within this sample. Nevertheless, the validity of this exclusion restriction is debatable and our IV results must be interpreted cautiously.

Table 5 reports the 2SLS regression results. The first stage coefficients of panel B and F-statistics suggest strong instruments. Estimates of the instrumented scope measures of panel A suggest a negative effect of broader patent scope on the probability of PIV entry: A 10 percentage increase in the count of Markush groups in the first independent claim decreases the probability of PIV entry by some two percentage points. Additional words in the first independent claim perform similarly, supporting the argument advanced by Kuhn and Thompson (2019) about a positive relationship between claim length and scope in the case of pharmaceutical patents. A 10 percent increase in the count of conjunctions "or" in the first independent claim makes a successful PIV challenge less likely by around one percentage point. These coefficients of the scope measures are statistically significant 
but smaller in magnitude compared to the OLS estimates reported in Table 8 in Appendix A.4. Such an upward bias in the OLS estimates could arise, e.g., if originator firms seek broader protection for more valuable drugs which, at the same time, attract more PIV challenges.

Table 5: Patent Scope and PIV Entry: IV Estimates.

\begin{tabular}{|c|c|c|c|c|}
\hline & $(1)$ & $(2)$ & $(3)$ & $(4)$ \\
\hline \multicolumn{5}{|l|}{ PANEL A: Second stage estimates } \\
\hline \multicolumn{5}{|l|}{ Instrumented variables: } \\
\hline $\log ($ Markush groups +1$)$ & $\begin{array}{c}-0.220^{* *} \\
(0.090)\end{array}$ & & & \\
\hline $\log ($ Conjunctions "or" +1$)$ & & $\begin{array}{c}-0.105^{* *} \\
(0.052)\end{array}$ & & \\
\hline $\log$ (Words) & & & $\begin{array}{c}-0.237^{* *} \\
(0.095)\end{array}$ & \\
\hline $\log$ (Independent claims) & & & & $\begin{array}{c}0.069 \\
(0.132)\end{array}$ \\
\hline \multicolumn{5}{|l|}{ PANEL B: First stage estimates } \\
\hline Instruments: & & & & \\
\hline $\log ($ Examiner historical average of Markush groups +1$)$ & $\begin{array}{c}0.239^{* * *} \\
(0.048)\end{array}$ & & & \\
\hline $\log ($ Examiner historical average of conjunctions "or" +1$)$ & & $\begin{array}{c}0.225^{* * *} \\
(0.034)\end{array}$ & & \\
\hline $\log$ (Examiner historical average of words) & & & $\begin{array}{c}0.238^{* * *} \\
(0.062)\end{array}$ & \\
\hline $\log$ (Examiner historical average of independent claims) & & & & $\begin{array}{c}0.242^{* * *} \\
(0.073) \\
\end{array}$ \\
\hline Observations & 3445 & 3445 & 3445 & 3447 \\
\hline First stage F-statistic & 25.286 & 44.860 & 14.523 & 10.934 \\
\hline Technology Center FE & $\times$ & $x$ & $\times$ & $x$ \\
\hline Filing year FE & $x$ & $x$ & $x$ & $x$ \\
\hline Drug controls & $\times$ & $\times$ & $\times$ & $x$ \\
\hline Exclusivity expiration year FE & $x$ & $x$ & $x$ & $x$ \\
\hline Patent controls & $\times$ & $\times$ & $\times$ & $x$ \\
\hline USPC FE & $x$ & $\times$ & $\times$ & $\times$ \\
\hline
\end{tabular}

Notes: This table reports the 2SLS estimates of the effects of patent scope on PIV entry. Panel A shows the main coefficient from the second stage regressions of the PIV entry indicator on the instrumented scope measures and controls. Panel B shows the main coefficient from the first stage regressions of the scope measures on the corresponding instruments and controls. The first stage F-statistic test is on the excluded instruments. FE stands for fixed effects. Drug controls include the indicators New chemical exclusivity, Orphan drug exclusivity, Pediatric exclusivity, Priority review, Capsule, Injectable, and Tablet. Patent controls include $\log ($ Effective length $), \log ($ Backward citations +1$), \log ($ Forward citations +1$), \log ($ Patent family size $)$, and the indicators Active ingredient patent, Method patent, and Continuing patent. We use a full sample of new drug patents for the regressions, and construct the instruments using data on all granted patents reviewed by the examiners of these new drug patents. Robust standard errors are reported in parentheses. ${ }^{*} p<0.10$, ${ }^{* *} p<0.05,{ }^{* * *} p<0.01$.

The question of whether or not independent claim count is a useful proxy for patent claim scope has been debated in the literature (see, e.g., Kuhn and Thompson, 2019 and Marco et al., 2019) for 
different points of view). Our coefficient estimate of the number of independent claims is close to zero in magnitude and statistically insignificant, suggesting that additional independent claims in a pharmaceutical patent fail to protect the patent against PIV challenges.

Robustness. Overall, we view the IV regression results as suggesting that broadening patent scope hinders PIV entry. We assess the robustness of the results to specification changes in Appendix A.4. The results remain unchanged when we exclude most of the control variables (Table 9) or include of an additional control for trends varying with the Technology Center (Table10).

We also use Art Unit fixed effects instead of Technology Center fixed effects (Table 11). The number of patents per Art Unit is typically small, only 21 on average. Reflecting this challenge, the point estimates from these specifications remain similar in magnitude compared to the main specifications with Technology Center fixed effects, but are less precisely estimated: only the coefficient of the word count remains statistically significant at the five percent level.

\section{Implications for Patent Policy}

Our empirical evidence suggests that longer effective patent length encourages PIV patent challenges, as predicted by the models of costly imitation. This effect weakens the efficiency of patent length as a policy tool to promote innovation. Our evidence also suggests that broader patent scope appears to hinder PIV entry.

However, these findings alone are not enough to characterize the optimal adjustments in patent length and scope. Ideally, we would also like to know whether or not incentives to develop new drugs are increasing in patent length. In the absence of a direct test of incentives to develop new

drugs, we resort to the formula $f\left(p_{G}^{*}\right):=\epsilon_{p}-p_{G}^{*} /\left(1-p_{G}^{*}\right)$ developed in Section 2. The sign of $f\left(p_{G}^{*}\right)$ not only tells us whether incentives to develop new drugs are increasing or decreasing in patent length but also whether patent length and scope are substitutable or complementary policy tools.

In our data the average probability of PIV entry is 0.17 (see Table 1), which directly provides an estimate of $p_{G}^{*}$. We develop two approaches to recover $\epsilon_{p}$, the elasticity of the generic firms' marginal cost function (see equation (1)): one based on the estimated elasticity of PIV entry with respect to effective patent length, $\xi_{T}:=\left(\partial p_{G} / p_{G}\right) /(\partial T / T)$, and another on the corresponding elasticity with respect to patent scope, $\xi_{b}:=\left(\partial p_{G} / p_{G}\right) /(\partial b / b)$.

Recovering $\epsilon_{p}$ via Patent Length Estimates. In Appendix A.5, we show that $\epsilon_{p}$ can be 
written as

$$
\epsilon_{p}=\frac{e^{-r T} r T}{\left(1-e^{-r T}\right) \xi^{T}}
$$

Hence, to calculate $\epsilon_{p}$, we need values for $r, T$ and $\xi_{T}$.

We set $r=0.05$. The same value of the firms' discount rate is also used, e.g., by Judd et al. (2012) in a similar context. Next, since the average effective patent length in our data (see Table $1)$ is 12.59 , we set $T=12.59$. These numerical values yield $r T \approx 0.63$. Denicolò $(2007)$ suggests that for an average patent across all industries, $r T \in[0.6,1.39]$.

Finally, to obtain a value for $\xi_{T}$, we compare estimates of $\beta_{2}$ of equation (19) in columns (1)-(5) of Table 3 to the average probability of PIV entry, 0.17. This comparison suggests that TRIPS reduced the rate of PIV entry by 47-65 percent. These figures, together with the estimated effect of TRIPS on effective patent length (-17 percent) reported in column (6) of Table 3, suggest that the elasticity $\xi_{T}$ could be between $47 / 17 \approx 2.76$ and $65 / 17 \approx 3.82$. We use the mean value of this range and set $\xi_{T}=3.29$. Inserting $\xi_{T}=3.29, r=0.05$, and $T=12.59$ into equation (21) gives $\epsilon_{p} \approx 0.22$.

Recovering $\epsilon_{p}$ via Patent Scope Estimates. Our regressions of the PIV entry indicator on the logged patent scope measures imply that an estimate of $\xi_{b}$ can directly be obtained by dividing an estimated coefficient of a log scope measure by the average probability of PIV entry, 0.17 . The statistically significant coefficient estimates of the IV regressions (columns (1)-(3) of Panel A of Table 5) suggest that $\xi_{b} \in[-0.65,-1,41]$. Using the average value of this range, we set $\xi_{b}=-1.03$.

To link $\xi^{b}$ with $\epsilon_{p}$, we assume that the generic firm's cost function has the constant elasticity form used in Example 1 of Section 2, and further stipulate that $c(b)=c b$. Using this functional form, we show in Appendix A.5 that $\epsilon_{p}=-1 / \xi_{b}$. Thus, setting $\xi_{b}=-1.03$ gives $\epsilon_{p} \approx 0.97$.

Effect of Patent Length on Incentives to Develop New Drug. We have two alternative ways to calculate $\epsilon_{p}$ in the formula for $f\left(p_{G}^{*}\right)$ : using $\xi_{T}$ to generate $\epsilon_{p}$ yields $\epsilon_{p}=0.22$, whereas using $\xi_{b}$ yields $\epsilon_{p}=0.97$. Assuming that these calculations together mean that $\epsilon_{p} \in[0.22,0.97]$ and setting $p_{G}^{*}=0.17$, yields $f\left(p_{G}^{*}\right):=\epsilon_{p}-p_{G}^{*} /\left(1-p_{G}^{*}\right) \in[0.02,0,77]$. To conclude, the marginal cost of PIV entry appear to be sufficiently inelastic so that innovation incentives in the pharmaceutical industry are increasing in patent length, implying that patent length and scope are substitutes with regard to those innovation incentives.

Optimal Patent Policy. To complete the characterization of optimal policy, we should assess 
whether $f\left(p_{G}^{*}\right)$ is larger or smaller than $\epsilon_{b}$, the elasticity of the effect of patent scope on patent challenging costs (see equation (2)). We can estimate $\epsilon_{b}$ in a similar way as $\xi_{b}$. In Appendix A.5, we show that $\epsilon_{b}=1-1 / \xi_{b}$. Using $\xi_{b}=-1.03$ suggests that $\epsilon_{b} \approx 1.97$. Thus, $\epsilon_{b}$ is appears to be larger than our estimates of $f\left(p_{G}^{*}\right)$. In sum, our results suggest that $\epsilon_{b}>f\left(p_{G}^{*}\right)>0$, implying that the term of pharmaceutical patents should be made shorter and this shorter patent term should be compensated by broader patent scope.

Robustness. Our recommendations concerning the optimal changes to patent length and scope are based on some strong assumptions. If we base the optimal policy analysis on estimates of the effect of patent scope, our characterization of optimal policy is robust in the sense that all our estimates of $\xi_{b}$ suggest that $f\left(p_{G}^{*}\right)$ is firmly positive but below $\epsilon_{b}$. However, these estimates are based on a functional form assumption which we cannot test.

Using patent length estimates to generate the optimal policy recommendations requires no specific functional form of the generic firm's cost function, but requires values for the firms' discount rate, $r$, and for the effective patent length, $T$. Our estimates suggest that $f\left(p_{G}^{*}\right)$ is positive but close to zero. Hence, equations (9) and (21) imply that somewhat higher values of $r, T$, or $\xi_{T}$ than what we use would make $f\left(p_{G}^{*}\right)$ negative. For example, using our largest (in absolute value) estimate of $\beta_{2}$ of equation (19) from column (2) of Table 3 would make $\xi_{T}$ sufficiently high to render $f\left(p_{G}^{*}\right)$ slightly negative. (Using any other estimate of $\beta_{2}$ keeps $f\left(p_{G}^{*}\right)$ positive.) Moreover, we would get somewhat smaller estimates of $\epsilon_{p}$ (and hence of $f\left(p_{G}^{*}\right)$ ), if we used the estimated effects of AIPA instead of those of TRIPS. However, the interpretation of the effect of AIPA on effective patent length is somewhat ambiguous because of the earlier disclosure of patent applications in the post-AIPA period (see Appendix A.3).

Finally, a revealed-preference argument supports that $f\left(p_{G}^{*}\right)>0$ is more likely than $f\left(p_{G}^{*}\right)<0$ - if $f\left(p_{G}^{*}\right)$ were negative, it would be profitable for originator firms themselves to shorten the effective lengths of their patents. In Appendix A.3 we provide an example of this revealed-preference argument: we show how originator firms shy away from continuing patents with long grant lags after TRIPS and argue that such a behavior is consistent with $f\left(p_{G}^{*}\right)>0$ but not with $f\left(p_{G}^{*}\right)<0$.

We can conclude that $f\left(p_{G}^{*}\right)$ is likely to be small, smaller than $\epsilon_{b}$, but hardly negative. 


\section{Conclusion}

We characterize optimal patent policy for the pharmaceutical industry by only using data on pharmaceutical patents. Our results combining theory and evidence from DiD regressions exploiting variations in patent law, and IV regressions exploiting patent examiner leniency differences suggest that new drug patent length should be made shorter, while using broader patent scope to restore incentives to develop new drugs. The main channel leading to this conclusion is the positive effect of longer effective patent term on successful PIV patent challenges by generic entrants.

Our IV regression results concern patent claims, but broadening the scope of claims may be an awkward policy instrument. A more potential policy instrument to broaden pharmaceutical patent scope could be to restrict PIV challenges, e.g., by providing longer FDA exclusivity periods.

\section{References}

Abrams, D. S. (2009). Did trips spur innovation? an empirical analysis of patent duration and incentives to innovate. University of Pennsylvania Law Review, 157(6):1613-1647.

Belleflamme, P. and Peitz, M. (2015). Industrial Organization: Markets and Strategies. Cambridge University Press: Cambridge, UK, 2nd edition.

Boldrin, M. and Levine, D. K. (2013). The case against patents. Journal of Economic Perspectives, $27(1): 3-22$.

Branstetter, L., Chatterjee, C., and Higgins, M. J. (2016). Regulation and welfare: Evidence from paragraph IV generic entry in the pharmaceutical industry. RAND Journal of Economics, $47(4): 857-890$.

Budish, E., Roin, B. N., and Williams, H. (2015). Do firms underinvest in long-term research? evidence from cancer clinical trials. American Economic Review, 105(7):2044-85.

Budish, E., Roin, B. N., and Williams, H. (2016). Patents and research investments: Assessing the empirical evidence. American Economic Review: Papers \& Proceedings, 106(5):183-187.

Cockburn, I., Kortum, S., and Stern, S. (2003). Are all patent examiners equal? Examiners, patent 
characteristics, and litigation outcomes. In Cohen, W. and Merrill, S., editors, Patents in the Knowledge-Based Economy, pages 19-53. Washington, DC: The National Academies Press.

Denicolò, V. (1996). Patent races and optimal patent breadth and length. Journal of Industrial Economics, 44(3):249-265.

Denicolò, V. (2007). Do patents over-compensate innovators? Economic Policy, 22(52):679-729.

Farre-Mensa, J., Hegde, D., and Ljungqvist, A. (2020). What is a patent worth? Evidence from the U.S. patent "lottery". Journal of Finance, 75(2):639-682.

FDA (2004). Guidance for industry - listed drugs, 30-month stays, and approval of ANDAs and 505(b)(2) applications under Hatch- Waxman, as amended by the Medicare Prescription Drug, Improvement, and Modernization Act of 2003 - Questions and Answers. FDA Guidance Documents.

Fernandez, D. and Huie, J. (2003). Commentaries analyses — strategic balancing of patent and FDA approval processes to maximize market exclusivity. Asia-pacific Biotech News, 7(16):9971005.

Freilich, J. (2015). The uniformed topology of patent scope. Stanford Technology Law Review, 19:150.

Galasso, A. and Schankerman, M. (2015). Patents and cumulative innovation: Causal evidence from the courts. Quarterly Journal of Economics, 130(1):317-369.

Gallini, N. T. (1992). Patent policy and costly imitation. RAND Journal of Economics, 23(1):52-63.

Gallini, N. T. (2002). The economics of patents: Lessons from recent U.S. patent reform. Journal of Economic Perspectives, 16(2):131-154.

Gambardella, A., Harhoff, D., and Verspagen, B. (2008). The value of European patents. European Management Review, 5(2).

Giorcelli, M. and Moser, P. (2019). Copyrights and creativity: Evidence from Italian opera in the Napoleonic age. Journal of Political Economy, forthcoming. 
Harhoff, D. and Reitzig, M. (2004). Determinants of opposition against EPO patent grants - the case of biotechnology and pharmaceuticals. International Journal of Industrial Organization, 22(4):443-480.

Hemphill, C. S. and Sampat, B. N. (2011a). When do generics challenge drug patents? Journal of Empirical Legal Studies, 8(4):613-649.

Hemphill, C. S. and Sampat, B. N. (2011b). Earning exclusivity: Generic drug incentives and the Hatch-Waxman Act. Antitrust Law Journal, 77(3):947-989.

Johnson, D. K. N. and Popp, D. (2003). Forced out of the closet: The impact of the American Inventors Protection Act on the timing of patent disclosure. RAND Journal of Economics, 34(1):96-112.

Judd, K. L., Schmedders, K., and Yeltekin, S. (2012). Optimal rules for patent races. International Economic Review, 53(1):23-52.

Kuhn, J. M. and Thompson, N. C. (2019). How to measure and draw causal inferences with patent scope. International Journal of the Economics of Business, 26(1):5-38.

Kyle, M. K. and McGahan, A. M. (2012). Investments in pharmaceuticals before and after TRIPS. Review of Economics and Statistics, 94(4):1157-1172.

Lanjouw, J. O. and Schankerman, M. (2001). Characteristics of patent litigation: A window on competition. RAND Journal of Economics, 32(1):129-151.

Lanjouw, J. O. and Schankerman, M. (2004). Patent quality and research productivity: Measuring innovation with multiple indicators. Economic Journal, 114(495):441-465.

Lemley, M. A. and Moore, K. A. (2004). Ending the abuse of patent continuations. Boston University Law Review, 84(63):63-123.

Lemley, M. A. and Sampat, B. (2012). Examiner characteristics and patent office outcomes. The Review of Economics and Statistics, 94(3):817-827.

Lerner, J. (2009). The empirical impact of intellectual property rights on innovation: Puzzles and clues. American Economic Review, 99(2):343-348. 
Marco, A. C., Sarnoff, J. D., and deGrazia, C. A. (2019). Patent claims and patent scope. Research Policy, 48(9):103790.

Maurer, S. M. and Scotchmer, S. (2002). The independent invention defence in intellectual property. Economica, 69(276):535-547.

Merges, R. P. and Nelson, R. R. (1990). On the complex economics of patent scope. Columbia Law Review, 90(4):839-916.

Moser, P. (2005). How do patent laws influence innovation? Evidence from nineteenth-century world's fairs. American Economic Review, 95(4):1214-1236.

Moser, P. (2013). Patents and innovation: Evidence from economic history. Journal of Economic Perspectives, 27(1):23-44.

Nordhaus, W. D. (1969). Invention Growth, and Welfare: A Theoretical Treatment of Technological Change. The MIT Press: Cambridge, MA.

Nordhaus, W. D. (1972). The optimum life of a patent: Reply. American Economic Review, $62(3): 428-431$.

Okada, Y., Naito, Y., and Nagaoka, S. (2016). Claim length as a value predictor of a patent. IIR Working Paper.

Onakpoya, I. J., Heneghan, C. J., and Aronson, J. K. (2016). Post-marketing withdrawal of 462 medicinal products because of adverse drug reactions: A systematic review of the world literature. BMC Medicine, 14(1):10.

Quian, Y. (2007). Do national patent laws stimulate domestic innovation in a global patenting environment? A cross-country analysis of pharmaceutical patent protection, 1978-2002. Review of Economics and Statistics, 89(3):436-453.

Righi, C. and Simcoe, T. (2019). Patent examiner specialization. Research Policy, 48(1):137-148.

Sakakibara, M. and Branstetter, L. (2001). Do stronger patents induce more innovation? evidence from the 1988 Japanese patent law reforms. RAND Journal of Economics, 32(1):77-100. 
Sampat, B. and Williams, H. L. (2019). How do patents affect follow-on innovation? Evidence from the human genome. American Economic Review, 109(1):203-236.

Takalo, T. (1998). Innovation and imitation under imperfect patent protection. Journal of Economics, 67(3):229-241.

Wright, D. J. (1999). Optimal patent breadth and length with costly imitation. International Journal of Industrial Organization, 17(3):419-436.

Yin, N. (2017). Pharmaceuticals, incremental innovation and market exclusivity. Mimeo.

\section{Appendix}

\section{A.1 Appendix to the Theoretical Model}

\section{A.1.1 Proof of Proposition 3}

Using equation (6), which determines $p_{B}^{*}(b, T)$, in applying the implicit function theorem to equation (15) yields

$$
\frac{\partial T}{\partial b}=-\frac{\partial V^{P} / \partial b}{\partial V^{P} / \partial T}
$$

We may now re-express the planner's problem as $\max _{b \in[0, \infty)} V^{S}(b, T(b))$. Differentiating $V^{S}(b, T(b))$ with respect to $b$ gives

$$
\frac{d V^{S}}{d b}=\frac{\partial V^{S}}{\partial b}+\frac{\partial V^{S}}{\partial T} \frac{\partial T}{\partial b}
$$

After substituting equations (10) and (12) for equation (22), we get

$$
\frac{\partial T}{\partial b}=\frac{\left(1-e^{-r T}\right) \epsilon_{p}}{r e^{-r T}\left(1-p_{G}^{*}\right) f\left(p_{G}^{*}\right)} \frac{\partial p_{G}^{*}}{\partial b}
$$

Next, differentiating equation (13) with respect to $b$ gives

$$
\frac{\partial V^{S}}{\partial b}=\left[\left(1-e^{-r T}\right)\left(w_{2}-w_{1}\right)-\frac{\partial C_{G}}{\partial p_{G}}\right] \frac{\partial p_{G}^{*}}{\partial b}-\frac{\partial C_{G}}{\partial b} .
$$

Similarly, for $T$ we get

$$
\frac{\partial V^{S}}{\partial T}=-r e^{-r T}\left(1-p_{G}^{*}\right)\left(w_{2}-w_{1}\right)+\left[\left(1-e^{-r T}\right)\left(w_{2}-w_{1}\right)-\frac{\partial C_{G}}{\partial p_{G}}\right] \frac{\partial p_{G}^{*}}{\partial T},
$$

which can be rewritten after some algebra by using equations (1), (4), (7), and (9) as

$$
\frac{\partial V^{S}}{\partial T}=\frac{-r e^{-r T}}{\epsilon_{p}}\left[\left(w_{2}-w_{1}\right) f\left(p_{G}^{*}\right)\left(1-p_{G}^{*}\right)+p_{G}^{*} \pi_{2}\right] .
$$


After using equations (24)-(26), and some algebra, equation (23) can be written as

$$
\frac{d V^{S}}{d b}=-\frac{\partial p_{G}^{*}}{\partial b}\left[\frac{\partial C_{G}}{\partial p_{G}}+\frac{\left(1-e^{-r T}\right) \pi_{2} p_{G}^{*}}{f\left(p_{G}^{*}\right)\left(1-p_{G}^{*}\right)}\right]-\frac{\partial C_{G}}{\partial b} .
$$

By using equations (1), (2), (4), (8), and (9), this expression can be further rewritten as

$$
\frac{d V^{S}}{d b}=\frac{\partial C_{G}}{\partial b}\left[\frac{\epsilon_{b}}{f\left(p_{G}^{*}\right)}-1\right]
$$

Since $\partial C_{G} / \partial b>0$ by assumption, the sign of $d V^{S} / d b$ is given by the sign of the term in the square brackets of equation (27).

The optimal patent policy is characterized by the signs of equations (24) and (27). Equation (27) tells us the optimal direction of patent scope and equation (24) tells us the direction in which patent length needs to be adjusted so as to compensate a change in patent scope.

Let us first analyze the sign of equation (24). Proposition 1 implies that $\partial p_{G}^{*} / \partial b<0$. As a result, the sign of $\partial T / \partial b$ is given by the sign of $-f\left(p_{G}^{*}\right)$.

As to the sign of equation (27), the term in the square brackets of equation (27) is definitely negative if $f\left(p_{G}^{*}\right)<0$ and, as a result, $d V^{S} / d b<0$. If $f\left(p_{G}^{*}\right)>0$, then the first term in the square brackets of equation (27) is positive. Then the term in the square brackets is negative if $\epsilon_{b}<f\left(p_{G}^{*}\right)$, and positive if $\epsilon_{b}>f\left(p_{G}^{*}\right)$.

To summarize: i) If $f\left(p_{G}^{*}\right)<0, \partial T / \partial b>0$ and $d V^{S} / d b<0$. Thus, it is optimal to reduce both patent scope and patent length; ii) If $\epsilon_{b}>f\left(p_{G}^{*}\right)>0, \partial T / \partial b<0$ and $d V^{S} / d b>0$. Thus, it is optimal to increase patent scope and reduce patent length; iii) If $f\left(p_{G}^{*}\right)>\epsilon_{b}, \partial T / \partial b<0$ and $d V^{S} / d b<0$. Thus, it is optimal to reduce patent scope and increase patent length.

\section{A.1.2 Results Without Assumption 1}

As the main text characterize results for the case $\partial^{2} C_{G} / \partial p_{G} \partial b>0$, we here focus on the case $\partial^{2} C_{G} / \partial p_{G} \partial b \leq 0$. The proofs of Proposition 1 and 2 imply that if $\partial^{2} C_{G} / \partial p_{G} \partial b=0$, changes in patent scope have no impact on the incentives of the generic and originator firms and, if $\partial^{2} C_{G} / \partial p_{G} \partial b<0$, an increase in patent scope increases incentives for patent challenges and reduces incentives for new drug development. The results of Proposition 1 and 2 concerning the effect of patent length remain unaffected.

We next analyse the optimal patent policy for $\partial^{2} C_{G} / \partial p_{G} \partial b \leq 0$, implying that $\epsilon \leq 0$. We first consider the case $\epsilon<0$, before moving to the case $\epsilon=0$.

When $\epsilon<0$, the counterpart to Proposition 3 can be expressed as follows:

Proposition 4: Assume that $\epsilon_{b}<0$. Then, i) if $f\left(p_{G}^{*}\right)>0$, it is optimal to reduce both patent length and patent scope; ii) If $\epsilon_{b}<f\left(p_{G}^{*}\right)<0$, it is optimal to reduce patent length and increase patent scope; iii) If $f\left(p_{G}^{*}\right)<\epsilon_{b}$, it is optimal to reduce patent scope and increase patent length.

Proof: The proof follows the proof of Proposition 3. The optimal policy is still characterized by the signs of equations (24) and (27). As before, equation (27) tells us the optimal direction of patent scope and equation (24) tells us the direction in which patent length needs to be adjusted so as to compensate the change in patent scope.

But now $\partial^{2} C_{G} / \partial p_{G} \partial b<0$ and, consequently, the proof of Proposition 1 implies that $\partial p_{G} / \partial b>$ 0 . As a result, equation (24) shows that the sign of $\partial T / \partial b$ is given by the sign of $f\left(p_{G}^{*}\right)$. 
Note next from equation (27), that if $f\left(p_{G}^{*}\right)>0$, then $d V^{S} / d b<0$ because because $\epsilon_{b}<0$. If $f\left(p_{G}^{*}\right)<0$, the first term in the square brackets of equation (27) is positive. Then the term in the square brackets is positive if $\epsilon_{b}<f\left(p_{G}^{*}\right)$, implying $d V^{S} / d b>0$, and negative if $\epsilon_{b}>f\left(p_{G}^{*}\right)$, implying $d V^{S} / d b<0$.

To summarize: i) If $f\left(p_{G}^{*}\right)>0, \partial T / \partial b>0$ and $d V^{S} / d b<0$. Thus, it is optimal to reduce both patent scope and patent length; ii) If $\epsilon_{b}<f\left(p_{G}^{*}\right)<0, \partial T / \partial b<0$ and $d V^{S} / d b>0$. Thus, it is optimal to increase patent scope and reduce patent length; iii) If $f\left(p_{G}^{*}\right)<\epsilon_{b}, \partial T / \partial b<0$ and $d V^{S} / d b<0$. Thus, it is optimal to reduce patent scope and increase patent length.

To understand Proposition 4, recall that if $\epsilon_{b}<0$, an increase in patent scope has counterintuitive effects: Even if an increase in patent scope continues to make patent challenging more expensive, it has a positive effect on incentives for patent challenging and, consequently, a negative impact on incentives to develop new drugs. With this observation, the explanation of Proposition 4 is analogous to the one of Proposition 3.

Finally, let us consider the case $\epsilon_{b}=0$. To simplify the analysis, we use a standard relationship between welfare flow and market structure and define $w_{N}:=N \pi_{N}+c s_{N}$ in which $N \pi_{N}$ and $c s_{N}$ are industry profits and consumer surplus (when $N \in\{0,1,2\}$ drugs are competing in the market), respectively. Furthermore, define $T^{\prime}:=\arg \max p_{B}^{*}(T)$ and assume that the conditions stipulated in Section 2.2, $\partial f / \partial p_{G}<0$ and $\lim _{T \rightarrow \infty} f\left(p_{G}^{*}(T)\right)<0$, hold. Then $T^{\prime}$ is a finite and strictly positive unique solution to $f\left(p_{G}^{*}\left(T^{\prime}\right)\right)=0$. Under these assumptions, we get the following result:

Proposition 5: Assume that $\epsilon_{b}=0$. Then, patents should have a minimum scope. The optimal patent duration is given by $T^{*}:=\arg \max _{T} W(T)$ in which $T^{*}<T^{\prime}$.

Proof: Differentiate first $W(b, T)$ from equation (14) with respect to $b$. Note here that when $\epsilon_{b}=0, \partial^{2} C_{G} / \partial p_{G} \partial b=0$, and $\partial p_{B}^{*} / \partial b=0$. As a result, the sign of $\partial W(b, T) / \partial b$ is given by the sign of $\partial V^{S} / \partial b$. Since $\partial p_{G}^{*} / \partial b=0$, equation (25) implies that $\partial V^{S} / \partial b=-\partial C_{G} / \partial b<0$. Thus, it is optimal to have as narrow patents as possible.

Since $\partial p_{B}^{*} / \partial b=0$, equation (24) implies that $\partial T / \partial b=0$. As a result, $T$ is the only relevant dimension of the patent policy, and the socially optimal $T$ is given by $T^{*}:=\arg \max _{T} W(T)=$ $p_{B}^{*}(T) V^{S}(T)-C_{B}\left(p_{B}^{*}(T)\right)$. We next characterize the circumstances under which $T^{*}<\bar{T}$.

With the the help of equation (6), the first-order condition for the optimal $T$ can be written as

$$
\frac{\partial W}{\partial T}=\frac{\partial p_{B}^{*}(T)}{\partial T}\left[V^{S}(T)-V^{P}(T)\right]+p_{B}^{*}(T) \frac{\partial V^{S}(T)}{\partial T}=0 .
$$

Let us first prove that $V^{S}(T)-V^{P}(T)>0$, i.e., that the social value of a new drug is larger than its private value. If $V^{P}(T) \geq V^{S}(T)$, the issue of the patent policy design would be moot. However, since the social value of the new drug includes the costs of generic entry, the question of whether $V^{S}(T)>V^{P}(T)$ holds is not trivial. Substracting equation (5) from equation (13) yields

$$
\begin{aligned}
& V^{S}(T)-V^{P}(T) \\
= & \left(1-e^{-r T}\right)\left[\left(1-p_{G}^{*}(T)\right)\left(w_{1}-\pi_{1}\right)+p_{G}^{*}(T)\left(w_{2}-\pi_{2}\right)\right]+e^{-r T}\left(w_{2}-\pi_{2}\right)-C_{G}\left(p_{G}^{*}(T)\right) .
\end{aligned}
$$

From equation (3) we observe that $\Pi_{G}\left(p_{G}^{*}(T)\right) \geq 0$ implies that $\left(1-e^{-r T}\right) \pi_{2} p_{G}^{*}(T) \geq C_{G}\left(p_{G}^{*}(T)\right)$. Approximating the right-hand side of equation (29) downwards by substituting $\left(1-e^{-r T}\right) \pi_{2} p_{G}^{*}(T)$ for $C_{G}\left(p_{G}(T)^{*}\right)$ gives

$$
\begin{aligned}
& V^{S}(T)-V^{P}(T) \\
\geq & \left(1-e^{-r T}\right)\left[\left(1-p_{G}^{*}(T)\right)\left(w_{1}-\pi_{1}\right)+p_{G}^{*}(T)\left(w_{2}-2 \pi_{2}\right)\right]+e^{-r T}\left(w_{2}-\pi_{2}\right)>0,
\end{aligned}
$$


in which the last inequality follows from $w_{N}=N \pi_{N}+c s_{N}, N=1,2$.

Next, we evaluate $\partial W / \partial T$ at $T=T^{\prime}$. Then, $f\left(p_{G}^{*}\left(T^{\prime}\right)\right)=0$, and equation (26) implies that $\partial V^{S}\left(T^{\prime}\right) / \partial T<0$. From the proof of Proposition 2 we also observe that when $f\left(p_{G}^{*}\left(T^{\prime}\right)\right)=0$, $\partial p_{B}^{*}\left(T^{\prime}\right) / \partial T=0$. As a result, equation $(28)$ shows that $\partial W\left(T^{\prime}\right) / \partial T<0$.

Assume then that i) $\partial^{2} W / \partial T^{2}<0$ for all $T$ so that the problem is well-behaving. Assume further that ii) $\partial W(0) / \partial T>0$. A sufficient condition for ii) is $\partial p_{B}^{*}(0) / \partial T>p_{B}^{*}(0)$. To see this, note first from equation (4) that $p_{G}^{*}(0)=0$. Then, when evaluating $\partial W / \partial T$ at $T=0$ by using equations (26) and (29) we get

$$
\frac{\partial W(0)}{\partial T}=\frac{\partial p_{B}^{*}(0)}{\partial T}\left(w_{2}-\pi_{2}\right)-p_{B}^{*}(0) r\left(w_{2}-w_{1}\right),
$$

in which, as indicated by equations, (5), (6), and (11), $\partial p_{B}^{*}(0) / \partial T>0$ and $p_{B}^{*}(0)>0$. Clearly, $w_{2}-\pi_{2}>r\left(w_{2}-w_{1}\right)$.

If both conditions i) and ii) hold, then there exists exactly one solution for equation (28) in the range where $T \in\left(0, T^{\prime}\right)$ and this solution characterizes the maximum. Note for completeness, that if condition ii) fails to hold, but condition i) holds, then the optimal policy is to set $T^{*}=0$. If condition i) fails to hold, then there may be multiple solutions to equation (28). If condition ii) nonetheless holds, there must at least be one local maximum in the range where $T \in\left(0, T^{\prime}\right)$.

The explanation of Proposition 5 is the following: Since $\epsilon_{b}=0$, changes in patent scope have no impact on incentives for new drug development, and an increase in patent scope only increases the costs of generic firms with no welfare benefits. As a result, it is optimal to have narrow patents.

When changes in patent scope have no impact on incentives for new drug development, patent length becomes the only relevant patent policy tool. The social planner faces the classic Nordhausian patent length design problem with the twist that an increase in patent length increases incentives to challenge new drug patents, creating wasteful costs of patent challenging. Under some plausible restrictions on functional forms, the optimal length lies in the range $\left(0, T^{\prime}\right)$ in which patent length has a positive impact on incentives to develop new drugs and adverse impact on social welfare for a given level of drug development incentives.

Note that the proof of Proposition 5 is based on the assumptions guaranteeing that a finite $T^{\prime}$ solving $f\left(p_{G}^{*}\left(T^{\prime}\right)=0\right.$ exists. However, if no such $T^{\prime}$ exists, then Proposition 5 holds trivially since in that case $T^{\prime} \rightarrow \infty$.

\section{A.2 Data Construction}

In this appendix we describe the details of our data sources and variable construction. We also address the issue of missing observations in the outcome variable.

\section{A.2.1 FDA Approved Drugs Data: Orange Book and Drugs@FDA}

The main data for our empirical analysis comes from the FDA's publication Approved Drug Products with Therapeutic Equivalent Evaluations, commonly known as the Orange Book. We use the annual editions 21 - 33 (corresponding years 2001-2013) of the Orange Book. The editions $21-$ 32 in electronic format were received from the FDA through a Freedom of Information Act (FOIA) request. The $33^{r d}$ edition was downloaded from the FDA web-pages. ${ }^{7}$ The Orange Book digital publications consist of product, patent, and exclusivity data files. The product file identifies each drug with an FDA application number and, among others, lists information on active ingredient,

\footnotetext{
${ }^{7}$ The latest release of the Orange Book is available at: https://www.fda.gov/Drugs/InformationOnDrugs/ ucm129662.htm, last accessed on April 18, 2020.
} 
dosage form, strength, producer, trade name and approval date. The patent file lists the patents included in each drug application. If a drug is covered by the FDA exclusivity the type of exclusivity and its latest expiration date are listed in the exclusivity file. Using the drug application numbers we first link the Orange Book data files into one, and then link it with the early 2014 release of the Drugs@FDA database, Application and Product Tabs. ${ }^{8}$

The unit of observation in our analysis is a new drug patent. By definition, only new medicines, so called New Drug Applications (NDAs), may be listed in the Orange Book with corresponding patent information. Each patent thus protects an NDA. To account for the characteristics of NDAs, we aggregate drug application level data into the patent level observations. For example, if a patent protects a drug in a tablet form, we assign value one to the patent level indicator variable Tablet. The indicator variables for two other common drug forms, Capsule and Injectable, are calculated similarly. Some patents protect several active ingredients listed in the Orange Book. So we identify the first FDA-approved active ingredient protected by a given patent. We also identify the first FDA approval date of an NDA protected by a patent.

New chemical exclusivity is marked in the Orange Book by the code "NCE", and orphan drug exclusivity by the code "ODE", signifying a drug intended to treat rare conditions affecting less than 200,000 individuals in the US (21 U.S.C. $\S 360 \mathrm{bb}(2)$ ). Using these codes, we construct the indicator variables New chemical exclusivity and Orphan drug exclusivity measuring whether or not a patent protects a drug with new chemical or orphan drug exclusivity.

A drug receives pediatric exclusivity if its producer has conducted clinical trials and proved the safety and efficacy of its drug for children. In this case, additional six month of exclusive marketing rights are added to all existing patents and exclusivities covering the drug (21 U.S.C. § 355a(b)). A patent listed for an application with pediatric exclusivity has is recorded twice in the Orange Book: first, with the original patent number and its corresponding expiration date, and second, with the original patent number followed by a *PED" mark and a new expiration date six months later than the original expiration date. Based on "*PED" designations, we assign value one to the indicator variable Pediatric exclusivity if the patent protects a drug with pediatric exclusivity. Using the Orange Book, we also compute the latest FDA exclusivity year for each patent, and identify the patent expiration date.

We identify priority reviewed drugs from the Drugs@FDA database. Priority reviewed drugs are assessed by the FDA faster as they, if approved, would represent significant improvements over available therapy, and thus might be particularly valuable. During our data period, such drugs were marked by a letter "P" or "P*" in the Therapeutic Potential column of the Drugs@FDA Application Tab. Based on these codes, we construct the indicator variable Priority measuring whether or not a patent protects a drug that was priority reviewed by the FDA.

\section{A.2.2 Measuring Patent Challenges: FDA ANDA Approval Letters and Orange Book}

We measure generic entry via successful PIV challenges to new drug patents. In a PIV challenge, a generic firm seeks to enter prior to the expiration of a new drug patent by filing an Abbreviated New Drug Application (ANDA) to the FDA containing a certification that the new drug patent is invalid or noninfringed by the generic drug (21 U.S.C. § 355(j)(2)(A)(vii)(IV)). To construct the outcome variable, we first obtain the list of the approved ANDAs containing PIV certifications from the FDA through a FOIA request. To link this list with patent numbers, we seek the FDA's letters approving these ANDAs. Each originator drug is usually protected by multiple patents, and these approval letters specify all originator drug patents that have successfully been challenged. Some of

\footnotetext{
${ }^{8}$ The latest release of Drugs@FDA is available at: https://www.fda.gov/Drugs/InformationOnDrugs/ ucm079750.htm, last accessed on April 2, 2020.
} 
the letters are readily available from the FDA web-pages through the Drugs@FDA search engine. To collect more letters, we submit FOIA requests to the FDA. The data collection process has been slow, since the FDA only accepts a few FOIAs per month.

We read each approval letter and record patent numbers together with corresponding PIV certifications mentioned in the letters. Using patent numbers, we then link the data on PIV challenges from ANDA approval letters to the data on all new drug patents listed in the Orange Book. Some patents are challenged by multiple generics, so we calculate the earliest PIV ANDA approval date for each patent from the Orange Book files. We then construct our outcome variable, PIV entry, as an indicator which equals one if a new drug patent has successfully been challenged via PIV certification at least once.

PIV challenges by definition only concern patents before they expire. However, six patents in our sample are listed in the FDA approval letters as challenged through PIV certification even though the patents expired before the approval of the first generic drug. For consistency, we classify them as non-challenged, but the results do not significantly change if we assign them as challenged.

Missing Observations in PIV Challenged Patent Numbers. Some of the PIV challenged patent numbers are missing from our dataset. The FDA provided us with a list of 1020 ANDAs containing PIV certifications and we have collected the 677 approval letters for these ANDAs. There are thus 343 ANDAs in our sample for which the exact numbers of challenged patents are missing.

While we continue to file the FOIA requests to the FDA so as to update the data, we believe that our estimation sample is comprehensive enough to allow for an accurate measurement of both our outcome variable, PIV entry, and its timing: First, to measure PIV entry correctly, we only have to observe one of potentially many successful challenges of a new drug patent. Second, we aggregate the challenges to the active ingredient level, and measure whether or not we observe both 180-day generic exclusivity and a PIV challenged patent for each challenged active ingredient. That 180-day exclusivity is granted to the first filer of an ANDA and reliably measures the first successful PIV challenge of an active ingredient. ANDAs which have received 180-day exclusivity are marked by "PC" designation in the Orange Book. Our sample includes 1009 unique active ingredients and 150 of them are associated with ANDAs holding 180-day exclusivity. Out of those 150 active ingredients, we fail to observe a PIV challenged patent number only in 13 cases. Third, when looking at those 150 PIV challenged active ingredients, the average year of the first PIV entry is in practice the same regardless of whether we calculate it based on the earliest approval date of generic drugs with 180day exclusivity or based on the earliest approval date of generic drugs with non-missing challenged patent numbers. This evidence suggests that we also measure the timing of (the first) PIV entry reliably. Fourth, when filing the FOIA requests to the FDA in stages, we have randomized over the target ANDA approval letters. As a result, each month we receive approval letters of several randomly chosen ANDAs and add the challenged patent numbers from these letters to our sample. For some time now, our outcome variable of interest, PIV entry, has remained virtually unchanged as we add missing patent numbers.

\section{A.2.3 Measuring Effective Patent Length, Grant Lags, PTAs, and Some Patent Char- acteristics: USPTO PatEx and Orange Book}

Effective Patent Length. Our primary measure of the effective length of patent $i$ is

$$
\text { Effective length }_{i}=\text { Expiration date }_{i}-\max \left\{\text { Grant date }_{i}, \text { Drug approval date } \text { de }_{i}\right\}
$$

in which Expiration date ${ }_{i}$ is the date when patent $i$ expired, Drug approval date is $_{i}$ the date when the FDA approved the first of potentially many new drugs protected by patent $i$, and Grant date $i$ is the date when the USPTO issued patent $i$. We identify patent grant dates from the Application 
Data Tab of the USPTO PatEx, and the FDA approval and patent expiration dates from the product and patent files, respectively, of the Orange Book.

Patent Grant Lags. We calculate the grant lag of patent $i$ simply as

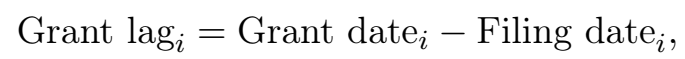

in which Filing date ${ }_{i}$ is the date on which USPTO received the application that was subsequently issued as patent $i$. Like grant dates, we identify patent filing dates and application numbers from the Application Data Tab of PatEx.

PTAs. We use patent application numbers to collect PTAs from the Patent Term Adjustment Tab of PatEx. Compensations for patent term forgone due to the USPTO regulatory delays are labeled as patent term extensions for patents filed after the adoption of TRIPS on June 8, 1995 but before the implementation of AIPA, on May 29, 2000, after which the compensations are labeled as patent term adjustments. ${ }^{9}$ For brevity and following the variable label in the PatEx files, we call both of these term modifications PTAs.

Other Patent Characteristics from PatEx. We assign the value one to the indicator variable Continuing patent ${ }_{i}$ if patent $i$ has been filed as a continuation, a continuation-in-part or a divisional application. We identify this information using application numbers from the Continuity Data Tab of PatEx where continuation, continuation-in-part and divisional applications are recorded as "CON", "CIP" and "DIV", respectively.

We use the Application Data Tab of PatEx to retrieve the USPC numbers and patent examiners' Art Unit codes. We identify the Technology Centers from the first two digits of the Art Unit codes. As the number of patents and their examiners in some Technology Centers is relatively small, we combine patents prosecuted in the Technology Centers that have issued less than 100 new drug patents into one group (with 188 patents).

\section{A.2.4 Measuring Claim Scope: USPTO Patent Claims Research Dataset}

Our measures of patent claim scope are the count of words, the counts of Markush groups and conjunctions "or" in the first independent claim, and the count of independent claims in each patent. The data on these measures of claim scope is available from the USPTO Patent Claims Research Dataset and we link it to our main dataset using patent numbers.

We instrument these measures of claim scope with the "examiner's historical average" calculated according to equation (20). To construct the instruments, we first identify the examiners of new drug patents from the Application Tab of PatEx. We then find all patents reviewed by these examiners and link the data using the patent number to the USPTO Patent Claims Research Dataset. Finally, we identify the scope outcomes for all granted patents reviewed by these examiners.

\section{A.2.5 Measuring Method and Active Ingredient Patents: Google Patent}

We combine text recognition algorithms and manual verification to identify method and active ingredient patents. Our classification approach employs the texts of the abstracts and first claims of patents. We collected the full texts of patent abstracts and the first claims using Google Patent Search Engine and data scrapping algorithms (written in Python using BeautifulSoup and urlib2 packages.)

Method patents covering drugs mostly pertain to the method of use of a drug or the ultimate intended effect of a patented chemical. Typically the first claim of a method patent begins

\footnotetext{
${ }^{9}$ See, e.g., https://www.uspto.gov/web/offices/pac/mpep/s2720.html and https://www.uspto.gov/web/ offices/pac/mpep/s2730.html, last accessed on April 3, 2020.
} 
with a word "method" or "process". For example, the first claim of the USPTO patent number 4870105 begins with: "A method for inhibiting gastrointestinal absorption ...". Hence, we assign the Method patent ${ }_{i}$ dummy equal to one, if the text of the first claim of a patent begins with the words "method" or "process". We manually verified texts of multiple patents to ensure the accuracy of the assignment.

We assign the value one to the Active ingredient ${ }_{i}$ dummy if the first claim of a patent pertains a chemical formula. We classify the first claim as a chemical formula when its first four symbols are a combination of single letters, dashes, commas or digits, for example, "N,N" or "RR". Active ingredient ${ }_{i}$ also equals one if the first three words of the first claim indicate a chemical compound and its variations. Word combinations used in chemical compound patents are, e.g., "composition of matter", "compound", "chemical compound", "antiviral compound", "amine", and "peptide". We also identify patents claiming solid forms (crystallines) of compounds, derivatives of compounds, and some other cases based as active ingredient patents. (In identifying the active ingredient patents, we used Python package re and heavily relied on regular expressions.)

Manual checks suggest that most of the patents in our sample which our approach does not classify as methods nor active ingredients pertain to drug delivery systems, devices, or formulations.

\section{A.2.6 Measuring Backward and Forward Citations: USPTO PatFT}

We collect the data on forward and backward citations from PatFT using a Python algorithm. We define the variable Backward citations $_{i}$ as the total number of patent documents (including foreign) listed on under the headline "References Cited" of patent $i$ in our sample, and the variable Forward citations $i$ as the number of the US issued patents mentioning patent $i$ in their "References Cited" list. Forward citation data was collected from PatFT using "Referenced By" retrieval tool in October 2017.

\section{A.2.7 Measuring Patent Family: EPO Open Patent Services}

Various definitions of the patent family size are used in the literature. One commonly used definition of the patent family size (see, e.g., Lanjouw and Schankerman, 2004; Sampat and Williams, 2019) is the number of distinct countries where the same invention has been patented. We follow this definition and construct the variable Patent family size $i$ as follows: We first collect the "DOCDB simple patent families" of the new drug patents in our sample from the Open Patent Services of the EPO in October $2017^{10}$. To collect the data, we used an algorithm and the Application Programming Interface granted to authors by the EPO. (The algorithm is written in Python using epo_ops and xml packages).

A "DOCDB simple patent family" may contain multiple patents from one patent office since it, e.g., includes continuing patents in addition to their parent patents. To solve the problem, we count the unique countries based on the country codes, which are the two letters preceding patent numbers retrievable from the Open Patent Services (e.g., Canadian patents contain a prefix CA, Japanese JP, Finnish FI, etc.). Thus, even if the DOCDB simple patent family lists several patents with the country code JP, we count Japan in our family size variable only once.

\footnotetext{
${ }^{10}$ https://www.epo.org/searching-for-patents/helpful-resources/first-time-here/patent-families/docdb.html, last accessed on April 24, 2020
} 


\section{A.3 Patent Length Estimations: Robustness}

\section{A.3.1 Other Impacts of TRIPS and AIPA}

Besides the changes affecting the effective patent length described in Section 5.1, TRIPS and AIPA introduced other changes to the U.S. patent law. In what we analyze some of these other changes that could threaten our identification of the effects of the effective patent length on PIV entry, affect the interpretation of our results, or be used to further support our main results.

Provisional Patent Applications. Another major change associated with the implementation of TRIPS was the introduction of a provisional patent application as a simplified version of a regular utility patent application. Provisional applications include no claims nor description of prior art, are not subject to examination, and automatically expire after one year (35 U.S.C. $\S 111$ (b)). The purpose of a provisional application is to give priority rights on invention without starting the patent clock: If a regular utility patent application is filed for the same invention before the expiration of its provisional application, the priority date is the provisional application date but the patent term is calculated from the utility patent application date.

A threat to our identification might arise if the use of provisional applications varies across patents depending on their prosecution time. To address this concern, we first create the indicator Provisional application $_{i}$ which equals one if patent $i$ claims the priority date of a provisional application. We identify these patents based on the "PRO" designations listed in the Continuity Data Tab of PatEx. We then estimate the DiD model of equation (19) using the Provisional application ${ }_{i}$ indicator as the dependent variable.

The results reported in column (1) of Table 6 suggest that the introduction of provisional applications is unlikely to drive our results: we observe no systematic relationship between the probability of a patent claiming the priority date of a provisional application and its prosecution time in the different policy regimes. This conclusion is confirmed by another robustness check: when we estimate equation (19) using a sample that excludes all patents with Provisional application ${ }_{i}=1$,

the effects of TRIPS and AIPA, reported in column (1) of Table 7 in the next subsection, become, if anything, stronger and more precisely estimated than in Table 3. 
Table 6: Patent Law Changes and Patent Characteristics by Patent Grant Lag.

\begin{tabular}{lccccccc}
\hline \hline Outcome & $\begin{array}{c}\text { Provi- } \\
\text { sional } \\
(1)\end{array}$ & $\begin{array}{c}\text { Conti- } \\
\text { nuing } \\
(2)\end{array}$ & $\begin{array}{c}\text { log(Markush } \\
\text { groups }+1) \\
(3)\end{array}$ & $\begin{array}{c}\text { Active } \\
\text { ingredient } \\
(4)\end{array}$ & $\begin{array}{c}\text { log(Public } \\
\text { length) } \\
(5)\end{array}$ & $\begin{array}{c}\text { log(Family } \\
\text { size) } \\
(6)\end{array}$ & $\begin{array}{c}\log (\text { Backward } \\
\text { citations+1) } \\
(7)\end{array}$ \\
\hline Grant lag $\geq 3$ years & 0.000 & $0.076^{* *}$ & 0.030 & 0.001 & $-0.081^{* * *}$ & $-0.174^{*}$ & $0.385^{* * *}$ \\
& $(0.000)$ & $(0.030)$ & $(0.038)$ & $(0.033)$ & $(0.013)$ & $(0.091)$ & $(0.078)$ \\
Grant lag $\geq 3$ years, & & & & & & & \\
Post-TRIPS & 0.024 & $-0.138^{* *}$ & -0.032 & -0.012 & $-0.088^{* * *}$ & 0.013 & 0.140 \\
& $(0.030)$ & $(0.055)$ & $(0.054)$ & $(0.041)$ & $(0.023)$ & $(0.141)$ & $(0.123)$ \\
Grant lag $\geq 3$ years, & & & & & & & \\
Post-AIPA & 0.019 & $-0.193^{* * *}$ & -0.036 & $-0.063^{*}$ & $0.294^{* * *}$ & 0.216 & -0.078 \\
& $(0.045)$ & $(0.052)$ & $(0.058)$ & $(0.037)$ & $(0.026)$ & $(0.140)$ & $(0.133)$ \\
\hline Mean dep. variable & 0.214 & 0.589 & 0.247 & 0.226 & 2.777 & 1.905 & 2.760 \\
Observations & 3517 & 3517 & 3485 & 3517 & 3517 & 3511 & 3517 \\
\hline Filing year FE & $\times$ & $\times$ & $\times$ & $\times$ & $\times$ & $\times$ & $\times$ \\
\hline
\end{tabular}

Notes: This table reports estimates of the effects of TRIPS and AIPA on various patent characteristics. Columns (1)-(7) show coefficients from an OLS regression of the Provisional application indicator, the Continuing patent indicator, $\log$ (Markush groups +1 ), the Active ingredient patent indicator, $\log ($ Public length), $\log$ (Patent family size), and $\log ($ Backward citations +1$)$, respectively, on three different indicators for patents with at least a three-year grant lag and filing year fixed effects (FEs). Standard errors, in parentheses, are clustered at the level of patents protecting the same active ingredient. ${ }^{*} p<0.10,{ }^{* *} p<0.05,{ }^{* * *} p<0.01$.

Continuing Patents. In the case of continuing patents - which represent close to 60 percent of our sample (see Table 1) - TRIPS had an impact on the effective patent length besides those effects discussed in Section 5.1. Before TRIPS, the terms of continuing patents and other patents were calculated in the same way, implying that continuing patents typically expired later than their (earlier-filed) parent patents. After TRIPS, continuing patents expire simultaneously with their parent patent (35 U.S.C. $\$ 154$ (a)(2)). Thus, TRIPS shortened the effective patent length of continuing patents more than that of other patents, and this shortening is stronger for continuing patents prosecuted over three years. As a result, long patent prosecution times might incentivize originator firms to opt for separate patent applications instead of continuing applications after TRIPS. Supporting this idea, patents with long prosecution lags are less likely to be continuing after TRIPS, compared to other patents in our sample, as shown in column (2) of Table 6.

A smaller share of continuing patents in the post-TRIPS period of our sample has several implications: First, it implies a stronger variation in the effective patent length stemming from the variation in patent grant lags. Second, since continuing patent applications might be used as a tool to make patent protection stronger (see, e.g., Lemley and Moore 2004), it raises the concern that our baseline estimates of the effect of TRIPS on patents with long prosecution lags would partially reflect narrower patent protection. To address this concern, we estimate the DiD model of equation (19) using a sample of continuing patents. The results, reported in column (2) of Table 7, support our main result of the positive impact of longer effective patent length on the probability of PIV entry: the effects of TRIPS and AIPA on the patents prosecuted at least three years are stronger than in any other specification. The results in columns (3) (4), and (7), discussed at the end of the subsection, also mitigate the concern that potentially narrower patent protection in the post-TRIPS period would be driving our main results.

Third, taken together, the results in columns (2) of Table 6 and Table 7 suggest that TRIPS made continuing patents with long grant lags less valuable for originator firms even if it simultaneously 
reduced the threat of PIV challenges to these patents. We interpret these results as reflecting the strong negative effect of TRIPS on the effective length of continuing patents with long grant lags. Then, by revealed preference, the results also support our policy conclusion of Section (7) that $f\left(p_{G}^{*}\right)>0$ is more likely than $f\left(p_{G}^{*}\right)<0$ - if $f\left(p_{G}^{*}\right)$ were negative, we should have observed the proportion of continuing patents to increase in the post-TRIPS period.

Disclosure of Patent Applications. AIPA affected the timing of disclosure of patent applications (see, e.g., Johnson and Popp 2003). Prior to AIPA, a patent application in the US was not published until the patent was granted. AIPA harmonized disclosure in the US with international standards according to which a pending patent application is published 18 months after its filing date. For patents with long grant lags, the resulting loss in secrecy can be substantial, whereas patents granted (and, by implication, published) within 18 months loose practically nothing. Earlier disclosure of a patent application may lengthen the effective time for generic entry prior to the patent expiration, and hence affect the interpretation of our results concerning the effect of AIPA.

To evaluate the effects of AIPA on patent information disclosure in our setting, we measure the new drug patent length beginning from its disclosure. We define the public length of patent $i$ filed in year $t$ as

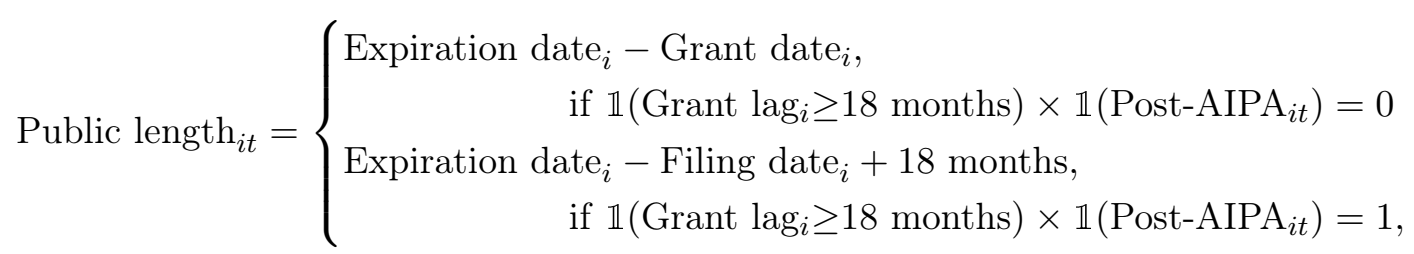

in which the indicator variable $\mathbb{1}$ (Grant $\operatorname{lag}_{i} \geq 18$ months) gets, analogous to $\mathbb{1}$ (Grant $\operatorname{lag}_{i} \geq 3$ years) of equation (19), value one if the grant lag of patent $i$ is at least 18 months.

Our calculation only provides a crude measure of the effect of AIPA on public patent length. For instance, the calculation ignores the disclosure of the US inventors' international applications after 18 months prior to AIPA, the exception to the post-AIPA publication requirement concerning applicants who waive the possibility of international patenting (35 U.S.C. $\S 122$ (b)(2)(B)(i)), and the requirement that the filing date of patent $i$ should be measured from its earliest filing date in the post-AIPA period (35 U.S.C. $\S 122(\mathrm{~b})(1)(\mathrm{A}))$.

We then estimate the DiD model of equation (19) using $\log \left(\mathrm{Public}_{\mathrm{i}} \mathrm{length}_{i}\right)$ as the dependent variable. Column (5) of Table 6 reports the results. Compared to the estimate reported in column (6) of Table 3 , the coefficient estimate of the term $\mathbb{1}\left(\right.$ Grant $\operatorname{lag}_{i} \geq 3$ years $) \times \mathbb{1}\left(\right.$ Post-AIPA $\left._{i t}\right)$ is now larger. While this result may arise from the imprecise measurement of public length, it may also indicate that an increase in public length partially contributes to the estimated positive effect of the longer effective length on PIV entry. Overall, however, estimates of the effects of TRIPS and AIPA depending on grant lags reported in column (6) of Table 3 and column (5) of Table 6 are similar.

Other Changes due to TRIPS and AIPA. Finally, we explore whether our results concerning the differential impacts of TRIPS and AIPA on PIV entry depending on prosecution lags could be explained by simultaneous differential changes in patent scope or value induced by various patent law modifications of TRIPS and AIPA. In this respect, estimates reported columns (3), (4), (6), and (7) of Table 6 are comforting: we observe no clear impacts of TRIPS and AIPA on the relationship between prosecution lags and patent scope or value, as measured by the count of Markush group in the first independent claim, the proportion of active ingredient patents, the patent family size, and the count of backward citations. 


\section{A.3.2 Other Subsamples and Specifications}

In Table 7, we provide further evidence that our results from the estimation of the DiD model of equation (19) are robust to using different subsamples and specifications. As discussed in the previous subsection, columns (1) and (2) report estimates using sample that only include patents which do not claim the priority date of a provisional application and continuing patents, respectively.

We study robustness to excluding related new drug patents. We identify all our sample patents sharing the same parent patent application using information on parent applications from the Continuity Data Tab of PatEx. The results in column (3) are generated by a sample that excludes all other new drug patents sharing the common parent application except for the latest one.

In column (4) the results arise from a sample that only includes patents for which we observe FDA exclusivity. These patents might be more valuable or - as our results of Table (2) indicate - more difficult to challenge than patents for which we observe no FDA exclusivity. Column (5) reports estimates from a model that, analogous to survival models, includes fixed effects to control for the length of exposure of a patent to PIV challenges. In this specification we, in addition to a full set of other controls, include a dummy measuring the time (in years) between the grant date of a patent and the earliest successful PIV patent challenge date or, in the absence of successful PIV challenges, the patent expiration date. Finally, we estimate a model that extends our baseline specification to allows for richer interactions between grant lags and patent policy reforms, and report the results in column (6).

The signs and magnitudes of the coefficient estimates reported in Table 7 are similar to those coefficients reported in columns (1)-(5) of Table 3. If anything, the effects of TRIPS and AIPA are now stronger and more precisely estimated. Coefficients of the additional interaction terms involving patents with a grant lag exceeding five years reported in Column (6) are imprecisely estimated, possibly because we have only 417 such patents in our sample. 
Table 7: PIV Entry and Patent Law Changes by Patent Grant Lag: Robustness Analysis.

\begin{tabular}{|c|c|c|c|c|c|c|}
\hline & (1) & $(2)$ & (3) & (4) & $(5)$ & (6) \\
\hline Grant lag $\geq 3$ years & $\begin{array}{c}0.025 \\
(0.025)\end{array}$ & $\begin{array}{c}0.030 \\
(0.029)\end{array}$ & $\begin{array}{c}0.016 \\
(0.029)\end{array}$ & $\begin{array}{c}0.032 \\
(0.031)\end{array}$ & $\begin{array}{l}0.040^{*} \\
(0.024)\end{array}$ & \\
\hline $\begin{array}{l}\text { Grant lag } \geq 3 \text { years, } \\
\text { Post-TRIPS }\end{array}$ & $\begin{array}{c}-0.123^{* * *} \\
(0.041)\end{array}$ & $\begin{array}{c}-0.180^{* * *} \\
(0.052)\end{array}$ & $\begin{array}{c}-0.126^{* * *} \\
(0.044)\end{array}$ & $\begin{array}{c}-0.118^{* *} \\
(0.046)\end{array}$ & $\begin{array}{c}-0.132^{* * *} \\
(0.035)\end{array}$ & \\
\hline $\begin{array}{l}\text { Grant lag } \geq 3 \text { years, } \\
\text { Post-AIPA }\end{array}$ & $\begin{array}{c}0.089^{* *} \\
(0.044)\end{array}$ & $\begin{array}{c}0.154^{* * *} \\
(0.051)\end{array}$ & $\begin{array}{c}0.105^{* *} \\
(0.041)\end{array}$ & $\begin{array}{c}0.087^{* *} \\
(0.039)\end{array}$ & $\begin{array}{c}0.090^{* * *} \\
(0.030)\end{array}$ & \\
\hline Grant lag $3-5$ years & & & & & & $\begin{array}{c}0.023 \\
(0.027)\end{array}$ \\
\hline $\begin{array}{l}\text { Grant lag } 3-5 \text { years, } \\
\text { Post-TRIPS }\end{array}$ & & & & & & $\begin{array}{c}-0.102^{* *} \\
(0.041)\end{array}$ \\
\hline $\begin{array}{l}\text { Grant lag } 3-5 \text { years, } \\
\text { Post-AIPA }\end{array}$ & & & & & & $\begin{array}{l}0.075^{*} \\
(0.039)\end{array}$ \\
\hline Grant lag $>5$ years & & & & & & $\begin{array}{c}0.033 \\
(0.039)\end{array}$ \\
\hline $\begin{array}{l}\text { Grant lag > } 5 \text { years, } \\
\text { Post-TRIPS }\end{array}$ & & & & & & $\begin{array}{c}-0.117 \\
(0.071)\end{array}$ \\
\hline $\begin{array}{l}\text { Grant lag > } 5 \text { years, } \\
\text { Post-AIPA }\end{array}$ & & & & & & $\begin{array}{c}0.065 \\
(0.063)\end{array}$ \\
\hline Mean dependent variable & 0.179 & 0.176 & 0.167 & 0.180 & 0.173 & 0.173 \\
\hline Observations & 2731 & 2054 & 2627 & 2668 & 3478 & 3483 \\
\hline R-squared & 0.233 & 0.268 & 0.210 & 0.262 & 0.385 & 0.234 \\
\hline Exposure length FE & & & & & $\bar{x}$ & \\
\hline Filing year FE & $x$ & $x$ & $\times$ & $x$ & $x$ & $\times$ \\
\hline Drug controls & $x$ & $x$ & $x$ & $x$ & $x$ & $x$ \\
\hline Exclusivity expiration year FE & $x$ & $x$ & $\times$ & $x$ & $x$ & $x$ \\
\hline Patent controls & $x$ & $x$ & $x$ & $x$ & $x$ & $x$ \\
\hline USPC FE & $x$ & $x$ & $x$ & $x$ & $x$ & $x$ \\
\hline Sample & $\begin{array}{l}\text { No prior } \\
\text { provisional }\end{array}$ & Continuing & $\begin{array}{l}\text { Latest } \\
\text { filed }\end{array}$ & $\begin{array}{c}\text { FDA } \\
\text { exclusivity }\end{array}$ & Full & Full \\
\hline
\end{tabular}

Notes: This table reports estimates of the effects of TRIPS and AIPA on PIV entry. Columns (1)-(5) show coefficients from an OLS regression of the PIV entry indicator on three and column (6) on five different indicators for patents with at least a three-year grant lag and controls. FE stands for fixed effects. Drug controls include the indicators New chemical exclusivity, Orphan drug exclusivity, Pediatric exclusivity, Priority review, Capsule, Injectable, and Tablet. Patent controls include $\log$ (Markush groups +1$), \log ($ Backward citations +1$), \log ($ Forward citations +1$), \log ($ Patent family size), and the indicators Active ingredient patent, Method patent, and Continuing patent. In columns (1)-(4) the samples exclude patents claiming the priority date of a provisional application, firstfiled patents covering the same invention, all but the latest-filed patents covering the same invention, and patents protecting drugs without FDA exclusivity, respectively. Standard errors, in parentheses, are clustered at the level of patents protecting the same active ingredient. ${ }^{*} p<0.10,{ }^{* *} p<0.05,{ }^{* * *} p<0.01$. 


\section{A.4 Patent Scope Estimations: Robustness}

In this section we explore the robustness of our patent claim scope estimates. Table 8 reports estimates of various claim scope measures from the OLS model of equation (18). Column (1) shows an estimate using the specification of column (3) in Table (2). We then replace the count of Markush groups in the first independent claim with alternative measures of patent claim scope: the count of the conjunction "or" in the first independent claim (column (2)), the count of words in the first independent claim (column (3)), the count of independent claims (column (4)). The coefficient estimate in colunm (3) suggests a statistically significant but small negative relationship between PIV entry and patent scope, as measure by the count of the conjunction "or" in the first independent claim. When compared with our IV estimates from Table (5), there appears to be an upward bias in most of these OLS estimates.

Tables (9)-(11) report the results from our exploration of the robustness of 2SLS estimates of patent scope measures. Tables (9) and (10) show that the results reported in Table (5) are robust, respectively, to the exclusion of control variables, and to the inclusion of the interaction of Technology Center fixed effects with filing year fixed effects, to control for Technology Center specific trends. Table (11) reports estimates from a regression in which we replace Technology Center fixed effects with Art Unit fixed effects. The number of patents per Art Unit is small, only 21 on average. Even if we group Art Units with less than 10 patents into one group of 266 patents, coefficients of the scope measures become less precisely estimated (although remaining similar in magnitude) than in Table (5). The only scope measure generating statistically significant effects is the count of words in the first independent claim, as shown by column (3) of Table (11)

We have also verified that our results are robust to using the following alternative measures of claim scope: the count of claims, and the counts of characters and the phrase "consisting of" in the first independent claim. We omit the regressions using these measures for brevity. 
Table 8: PIV Entry and Patent Scope: OLS Estimates.

\begin{tabular}{lcccc}
\hline \hline & $(1)$ & $(2)$ & $(3)$ & $(4)$ \\
\hline $\log ($ Markush groups+1) & -0.013 & & & \\
& $(0.012)$ & & & \\
$\log ($ Conjunctions "or" +1$)$ & & $-0.020^{* * *}$ & & \\
& & $(0.007)$ & & \\
$\log$ (Words) & & -0.001 & \\
& & & $(0.007)$ & \\
$\log ($ Independent claims) & & & & -0.009 \\
& & & & $(0.008)$ \\
\hline Mean dependent variable & 0.173 & 0.173 & 0.173 & 0.173 \\
Observations & 3483 & 3483 & 3483 & 3485 \\
R-squared & 0.242 & 0.241 & 0.243 & 0.241 \\
\hline Technology Center FE & $\times$ & $\times$ & $\times$ & $\times$ \\
Filing year FE & $\times$ & $\times$ & $\times$ & $\times$ \\
Drug controls & $\times$ & $\times$ & $\times$ & $\times$ \\
Exclusivity expiry year FE & $\times$ & $\times$ & $\times$ & $\times$ \\
Patent controls & $\times$ & $\times$ & $\times$ & $\times$ \\
USPC FE & $\times$ & $\times$ & $\times$ & $\times$ \\
\hline
\end{tabular}

Notes: This table reports coefficients from OLS regressions of the PIV entry indicator on measures of claim scope and controls. FE stands for fixed effects. Drug controls include the indicators New chemical exclusivity, Orphan drug exclusivity, Pediatric exclusivity, Priority review, Capsule, Injectable, and Tablet. Patent controls include log(Effective length), $\log ($ Backward citations +1$), \log ($ Forward citations +1$), \log ($ Patent family size), and the indicators Active ingredient patent, Method patent, and Continuing patent. Standard errors, in parentheses, are clustered at the level of patents protecting the same active ingredient. ${ }^{*} p<0.10$, ${ }^{* *} p<0.05,{ }^{* * *} p<0.01$. 
Table 9: PIV Entry and Patent Scope:

Robustness of IV Estimates to Exclusion of Control Variables.

\begin{tabular}{lcccc}
\hline \hline & $(1)$ & $(2)$ & $(3)$ & $(4)$ \\
\hline $\log$ (Markush groups+1) & $-0.244^{* * *}$ & & \\
& $(0.071)$ & & \\
$\log ($ Conjunctions "or" +1$)$ & & $-0.095^{* * *}$ & & \\
& & $(0.030)$ & & \\
$\log$ (Words) & & $-0.484^{* *}$ & \\
& & $(0.233)$ & \\
$\log$ (Independent claims) & & & -0.154 \\
& & & & $(0.123)$ \\
\hline Mean dependent variable & 0.173 & 0.173 & 0.173 & 0.173 \\
Observations & 3447 & 3447 & 3447 & 3449 \\
First-stage F-statistic & 41.446 & 127.960 & 5.417 & 15.264 \\
\hline Technology Center FE & $\times$ & $\times$ & $\times$ & $\times$ \\
Filing year FE & $\times$ & $\times$ & $\times$ & $\times$ \\
USPC FE & $\times$ & $\times$ & $\times$ & $\times$ \\
\hline
\end{tabular}

Notes: This table reports coefficients from 2SLS regressions of the PIV entry indicator on instrumented measures of claim scope and controls. The instruments are the cumulative averages of the scope measures of all patents reviewed by the examiner of a new drug patent, until one year preceding the filing year of the new drug patent. The first stage F-statistic tests is on the excluded instruments. FE stands for fixed effects, respectively. Robust standard errors are reported in parentheses. ${ }^{*} p<0.10,{ }^{* *} p<0.05$, *** $p<0.01$. 
Table 10: PIV Entry and Patent Scope:

Robustness of IV Estimates to Technology Center Specific Trends.

\begin{tabular}{|c|c|c|c|c|}
\hline & $(1)$ & $(2)$ & $(3)$ & $(4)$ \\
\hline $\log ($ Markush groups +1$)$ & $\begin{array}{c}-0.218^{* *} \\
(0.091)\end{array}$ & & & \\
\hline $\log ($ Conjunctions "or" +1$)$ & & $\begin{array}{c}-0.101^{*} \\
(0.052)\end{array}$ & & \\
\hline $\log$ (Words) & & & $\begin{array}{c}-0.219^{* *} \\
(0.091)\end{array}$ & \\
\hline $\log$ (Independent claims) & & & & $\begin{array}{c}0.062 \\
(0.132) \\
\end{array}$ \\
\hline Mean dependent variable & 0.173 & 0.173 & 0.173 & 0.173 \\
\hline Observations & 3445 & 3445 & 3445 & 3447 \\
\hline First-stage F-statistic & 24.520 & 43.897 & 14.769 & 10.592 \\
\hline Technology Center FE $\times$ Filing year FE & $x$ & $x$ & $x$ & $\times$ \\
\hline Drug controls & $x$ & $x$ & $x$ & $\times$ \\
\hline Exclusivity expiry year FE & $\times$ & $x$ & $x$ & $x$ \\
\hline Patent controls & $x$ & $x$ & $x$ & $x$ \\
\hline USPC FE & $\times$ & $\times$ & $\times$ & $\times$ \\
\hline
\end{tabular}

Notes: This table reports coefficients from 2SLS regressions of the PIV entry indicator on instrumented measures of claim scope and controls. The instruments are the cumulative averages of the scope measures of all patents reviewed by the examiner of a new drug patent, until one year preceding the filing year of the new drug patent. The first stage F-statistic tests is on the excluded instruments. FE stands for fixed effects. Drug controls include the indicators New chemical exclusivity, Orphan drug exclusivity, Pediatric exclusivity, Priority review, Capsule, Injectable, and Tablet. Patent controls include $\log$ (Effective length), $\log$ (Backward citations +1$), \log ($ Forward citations +1$), \log ($ Patent family size), and the indicators Active ingredient patent, Method patent, and Continuing patent. Robust standard errors in parentheses. ${ }^{*} p<0.10,{ }^{* *} p<0.05,{ }^{* * *} p<0.01$. 
Table 11: PIV Enry and Patent Scope:

Robustness of IV Estimates to Art Unit Fixed Effects.

\begin{tabular}{lcccc}
\hline \hline & $(1)$ & $(2)$ & $(3)$ & $(4)$ \\
\hline $\log ($ Markush groups +1$)$ & -0.257 & & & \\
& $(0.214)$ & & & \\
$\log ($ Conjunctions "or" +1$)$ & & -0.073 & & \\
& & $(0.065)$ & & \\
$\log$ (Words) & & $-0.190^{* *}$ & \\
& & & $(0.077)$ & \\
$\log ($ Independent claims) & & & & 0.117 \\
& & & & $(0.172)$ \\
\hline Mean dependent variable & 0.173 & 0.173 & 0.173 & 0.173 \\
Observations & 3445 & 3445 & 3445 & 3447 \\
First-stage F-statistic & 6.202 & 30.447 & 18.815 & 6.669 \\
\hline Art Unit FE & $\times$ & $\times$ & $\times$ & $\times$ \\
Filing year FE & $\times$ & $\times$ & $\times$ & $\times$ \\
Drug controls & $\times$ & $\times$ & $\times$ & $\times$ \\
Exclusivity expiration year FE & $\times$ & $\times$ & $\times$ & $\times$ \\
Patent controls & $\times$ & $\times$ & $\times$ & $\times$ \\
USPC FE & $\times$ & $\times$ & $\times$ & $\times$ \\
\hline
\end{tabular}

${ }^{1}$ Notes: This table reports coefficients from 2SLS regressions of the PIV entry indicator on instrumented measures of claim scope and controls. The instruments are the cumulative averages of the scope measures of all patents reviewed by the examiner of a new drug patent, until one year preceding the filing year of the new drug patent. The first-stage F-statistic tests is on the excluded instruments. FE stands for fixed effects. Drug controls include the indicators New chemical exclusivity, Orphan drug exclusivity, Pediatric exclusivity, Priority review, Capsule, Injectable, and Tablet. Patent controls include $\log$ (Effective length), $\log$ (Backward citations +1$), \log$ (Forward citations +1$), \log ($ Patent family size $)$, and the indicators Active ingredient patent, Method patent, and Continuing patent. Robust standard errors in parentheses. ${ }^{*} p<0.10,{ }^{* *} p<0.05,{ }^{* * *} p<0.01$. 


\section{A.5 Elasticity Calculations for Section 7}

Recall from Section 7 the definitions

$$
\xi_{j}:=\frac{\partial p_{G}}{\partial j} \frac{j}{p_{G}}, j \in\{b, T\} .
$$

We now prove the claims of Section 7 concerning the relation of $\xi_{j}$ to $\epsilon_{p}$ of equation (1), and to $\epsilon_{b}$ of equation (2).

Let us start with the relationship between $\xi_{T}$ and $\epsilon_{p}$. Using the first-order condition (4) to eliminate $\pi_{2}$ from equation (7) allows us to rewrite equation (7) as

$$
\frac{\partial p_{G}^{*}}{\partial T}=\frac{r e^{-r T}}{\left(1-e^{-r T}\right)} \frac{\partial C_{G} / \partial p_{G}}{\partial^{2} C_{G} / \partial p_{G}^{2}} .
$$

Multiplying both sides of this equation by $T / p_{G}^{*}$ gives

$$
\frac{\partial p_{G}^{*}}{\partial T} \frac{T}{p_{G}^{*}}=\frac{e^{-r T} r T}{\left(1-e^{-r T}\right)} \frac{\partial C_{G} / \partial p_{G}}{p_{G}^{*} \partial^{2} C_{G} / \partial p_{G}^{2}} .
$$

By using the definitions of the elasticities (1) and (30) this equation can be rewritten as

$$
\xi^{T}=\frac{e^{-r T} r T}{\left(1-e^{-r T}\right) \epsilon_{p}}
$$

i.e.,

$$
\epsilon_{p}=\frac{e^{-r T} r T}{\left(1-e^{-r T}\right) \xi^{T}} .
$$

This equation equals equation (21) of Section 7.

To link $\xi^{b}$ with $\epsilon_{p}$, we assume the functional form of the generic firm's cost function specified by equation (16), and further stipulate that $c(b)=c b$. Then, equation (16) can be expressed as

$$
C_{G}\left(p_{G}, b\right)=\frac{c b p_{G}^{\eta_{G}}}{\eta_{G}}
$$

Using equation (31) in equation (4) yields after some algebra

$$
p_{G}^{*}(b, T)=\left[\frac{\left(1-e^{-r T}\right) \pi_{2}}{c b}\right]^{\frac{1}{\eta_{G}-1}} .
$$

Differentiating equation (32) with respect to $b$ gives

$$
\frac{\partial p_{G}^{*}}{\partial b}=-\frac{1}{b}\left(\frac{1}{\eta_{G}-1}\right)\left[\frac{\left(1-e^{-r T}\right) \pi_{2}}{c b}\right]^{\frac{1}{\eta_{G}-1}} .
$$

Using equation (32) and multiplying both sides of the equation above by $b / p_{G}^{*}$ gives

$$
\frac{\partial p_{G}^{*}}{d b} \frac{b}{p_{G}^{*}}=\frac{1}{1-\eta_{G}}
$$


which may be rewritten by using equation (30) as

$$
\eta_{G}=1-\frac{1}{\xi_{b}}
$$

Using equation (16) in equation (1) implies that $\epsilon_{p}=\eta_{G}-1$ which, according to equation (33), is equivalent to $\epsilon_{p}=-1 / \xi_{b}$, as claimed in Section 7 .

Finally, our claim in Section (7) that $\epsilon_{b}=1-1 / \xi_{b}$ directly follows from equation (33) and from Example 1 of Section 2 where we show that $\epsilon_{b}=\eta_{G}$. 